\title{
Analysis of a Shock-Associated Noise Prediction Model Using Measured Jet Far-Field Noise Data
}

Milo D. Dahl

Glenn Research Center, Cleveland, Ohio

Jacob A. Sharpe

Saginaw Valley State University, University Center, Michigan 


\section{NASA STI Program . . . in Profile}

Since its founding, NASA has been dedicated to the advancement of aeronautics and space science. The NASA Scientific and Technical Information (STI) program plays a key part in helping NASA maintain this important role.

The NASA STI Program operates under the auspices of the Agency Chief Information Officer. It collects, organizes, provides for archiving, and disseminates NASA's STI. The NASA STI program provides access to the NASA Aeronautics and Space Database and its public interface, the NASA Technical Reports Server, thus providing one of the largest collections of aeronautical and space science STI in the world. Results are published in both non-NASA channels and by NASA in the NASA STI Report Series, which includes the following report types:

- TECHNICAL PUBLICATION. Reports of completed research or a major significant phase of research that present the results of NASA programs and include extensive data or theoretical analysis. Includes compilations of significant scientific and technical data and information deemed to be of continuing reference value. NASA counterpart of peer-reviewed formal professional papers but has less stringent limitations on manuscript length and extent of graphic presentations.

- TECHNICAL MEMORANDUM. Scientific and technical findings that are preliminary or of specialized interest, e.g., quick release reports, working papers, and bibliographies that contain minimal annotation. Does not contain extensive analysis.

- CONTRACTOR REPORT. Scientific and technical findings by NASA-sponsored contractors and grantees.
- CONFERENCE PUBLICATION. Collected papers from scientific and technical conferences, symposia, seminars, or other meetings sponsored or cosponsored by NASA.

- SPECIAL PUBLICATION. Scientific, technical, or historical information from NASA programs, projects, and missions, often concerned with subjects having substantial public interest.

- TECHNICAL TRANSLATION. Englishlanguage translations of foreign scientific and technical material pertinent to NASA's mission.

Specialized services also include creating custom thesauri, building customized databases, organizing and publishing research results.

For more information about the NASA STI program, see the following:

- Access the NASA STI program home page at http://www.sti.nasa.gov

- E-mail your question to help@sti.nasa.gov

- Fax your question to the NASA STI Information Desk at 443-757-5803

- Phone the NASA STI Information Desk at 443-757-5802

- Write to: STI Information Desk NASA Center for AeroSpace Information 7115 Standard Drive Hanover, MD 21076-1320 


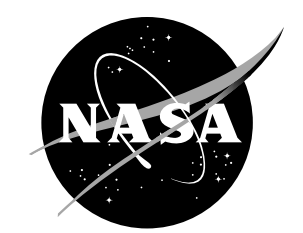

\section{Analysis of a Shock-Associated Noise Prediction Model Using Measured Jet Far-Field Noise Data}

Milo D. Dahl

Glenn Research Center, Cleveland, Ohio

Jacob A. Sharpe

Saginaw Valley State University, University Center, Michigan

Prepared for the

SciTech 2014

sponsored by the American Institute of Aeronautics and Astronautics

National Harbor, Maryland, January 13-17, 2014

National Aeronautics and

Space Administration

Glenn Research Center

Cleveland, Ohio 44135 


\section{Acknowledgments}

The authors would like to thank Dr. James Bridges for providing the measured data. The NASA High Speed Project of the Fundamental Aeronautics Program supported this work.

Trade names and trademarks are used in this report for identification only. Their usage does not constitute an official endorsement, either expressed or implied, by the National Aeronautics and Space Administration.

This work was sponsored by the Fundamental Aeronautics Program at the NASA Glenn Research Center.

Level of Review: This material has been technically reviewed by technical management.

Available from

NASA Center for Aerospace Information 7115 Standard Drive

Hanover, MD 21076-1320
National Technical Information Service 5301 Shawnee Road Alexandria, VA 22312 


\title{
Analysis of a Shock-Associated Noise Prediction Model Using Measured Jet Far-Field Noise Data
}

\author{
Milo D. Dahl \\ National Aeronautics and Space Administration \\ Glenn Research Center \\ Cleveland, Ohio 44135 \\ Jacob A. Sharpe \\ Saginaw Valley State University \\ University Center, Michigan 48710
}

\begin{abstract}
A code for predicting supersonic jet broadband shock-associated noise was assessed using a database containing noise measurements of a jet issuing from a convergent nozzle. The jet was operated at 24 conditions covering six fully expanded Mach numbers with four total temperature ratios. To enable comparisons of the predicted shock-associated noise component spectra with data, the measured total jet noise spectra were separated into mixing noise and shock-associated noise component spectra. Comparisons between predicted and measured shock-associated noise component spectra were used to identify deficiencies in the prediction model. Proposed revisions to the model, based on a study of the overall sound pressure levels for the shock-associated noise component of the measured data, a sensitivity analysis of the model parameters with emphasis on the definition of the convection velocity parameter, and a least-squares fit of the predicted to the measured shock-associated noise component spectra, resulted in a new definition for the source strength spectrum in the model. An error analysis showed that the average error in the predicted spectra was reduced by as much as $3.5 \mathrm{~dB}$ for the revised model relative to the average error for the original model.
\end{abstract}

\section{Introduction}

A jet noise prediction model must compute the radiated noise from all the sources that exist throughout the range of useful jet operating conditions. At lower speeds, the noise may be characterized as coming from the fine-scale turbulence in the flow. As the speed increases, the noise due to coherent, large-scale turbulence becomes significant starting in the directions off the downstream jet axis. Near sonic conditions and above, pressure imbalances in the flow create shocks. The interaction between turbulence and shocks creates an additional source of noise that radiates over a broad range of higher frequencies and predominantly in the direction upstream of the nozzle exit. If coherent feedback occurs, then intense screeching can also be present. These are all potential sources of radiated jet noise. An approach to making jet noise predictions is to model the sources separately. Then assuming incoherent sources, the radiated noise from each source is combined in the far field to obtain the total radiated noise. Once a modeling tool has been developed, it must be validated by comparing predictions to experimentally measured data.

As part of a larger study to assess NASA's capability to predict aircraft noise, empirical and acoustic analogy based tools were used to predict jet noise and the results were compared to measured data over a wide range of operating conditions. ${ }^{1}$ The jet experiments used nozzle geometries including convergent, convergentdivergent, internal mixer, separate flow, and chevron configurations operating with Mach numbers from 0.3 to 2.0 and temperatures from 0.8 to 3.0 times the ambient temperatures. The predicted jet noise included both mixing noise, for all jet operating conditions, and broadband shock-associated noise, for supersonic jet operating conditions. The general conclusions were that the empirical tools could make successful overall sound pressure level predictions for a broad range of nozzle geometries and operating conditions while the acoustic analogy tools were successful for a very limited range of operating conditions using a single stream 
nozzle. No attempt was made in the above study to separately assess the ability to predict the broadband shock-associated noise generated during supersonic jet flow conditions.

$\mathrm{Dahl}^{2}$ recently reported separate assessments of jet mixing noise and broadband shock-associated noise prediction codes. Included in that report was an assessment of the SAE broadband shock-associated noise prediction model that is documented in SAE ARP $876 \mathrm{E}^{3}$ and is also included within NASA's Aircraft Noise Prediction Program (ANOPP). ${ }^{4}$ The measured jet noise data used in the assessment were total farfield noise spectra decomposed into component spectra for mixing noise and shock-associated noise. The predicted shock-associated noise spectra were compared to the shock-associated noise component of the measured spectra. Favorable agreements were noted for the prediction codes with the exception of the SAE model code. This code gave predicted spectra that compared favorably to the total noise spectra in the upstream direction and became increasingly inaccurate at higher jet temperatures and downstream directions. According to the SAE document, the total predicted jet noise is the sum of the predictions from the mixing noise model and the shock-associated noise model. In all cases shown in Dahl, ${ }^{2}$ the addition of mixing noise to the SAE shock-associated noise code output would lead to inaccurate results especially at lower frequencies where mixing noise dominates the spectrum. This paper examines the SAE shockassociated noise prediction model using the shock-associated noise component of the measured data and proposes changes to the model. The model would then meet the intent stated in the SAE document of only predicting the shock-associated noise component of supersonic jet noise and that the total predicted radiated noise would be obtained by adding the predictions from a jet mixing noise model.

\section{Experimental Data}

The experimental jet noise spectral data used in this study were acquired during an extensive test program conducted using the Small Hot Jet Acoustic Rig (SHJAR) at the NASA Glenn Research Center. The SHJAR is a single-stream, hot jet rig installed within the Aero-Acoustic Propulsion Laboratory, a 65-foot geodesic dome lined with acoustic absorbing material to provide anechoic conditions for noise testing at all frequencies above $200 \mathrm{~Hz}$. More information on this facility may be found in Bridges \& Brown ${ }^{5}$ and other reports describe the types of data and the quality of the data collected during testing in this facility. ${ }^{6-8}$

Khavaran \& Bridges ${ }^{9}$ discuss details of the test results from the program to measure the noise from jets at a variety of nozzle pressure ratios and total temperatures. Tables are given that describe the different nozzles used and the variety of operating conditions tested. A subset of that data is used here consisting of noise data from supersonic jets issuing from a 2.0-inch exit diameter, circular, convergent nozzle. The nozzle, designated as smc021, is a modified version of the smc000 baseline convergent nozzle with a 5-degree conic contraction and a 0.04-inch thick lip, see Figure 1. The smc021 nozzle had a sharp edge lip with notches cut into the edge. These nozzles are shown in Figure 2. The purpose of the modifications was to minimize the screech noise observed in the smc000 nozzle spectral data. ${ }^{10}$

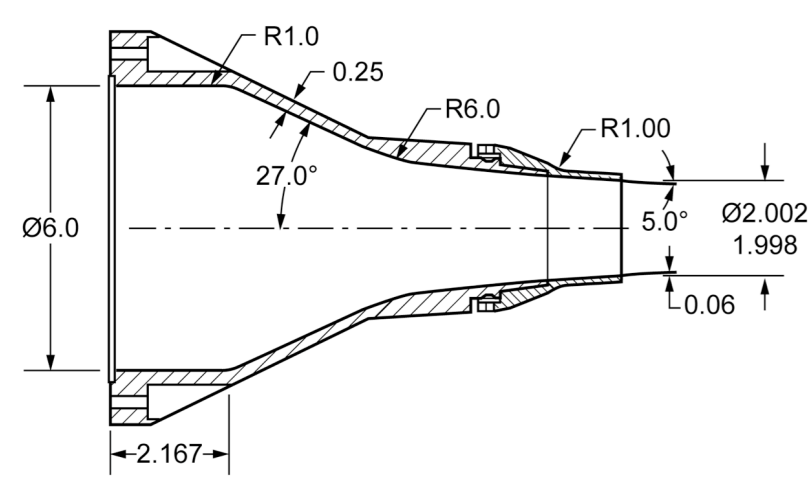

Figure 1. Diagram of the smc000 nozzle.

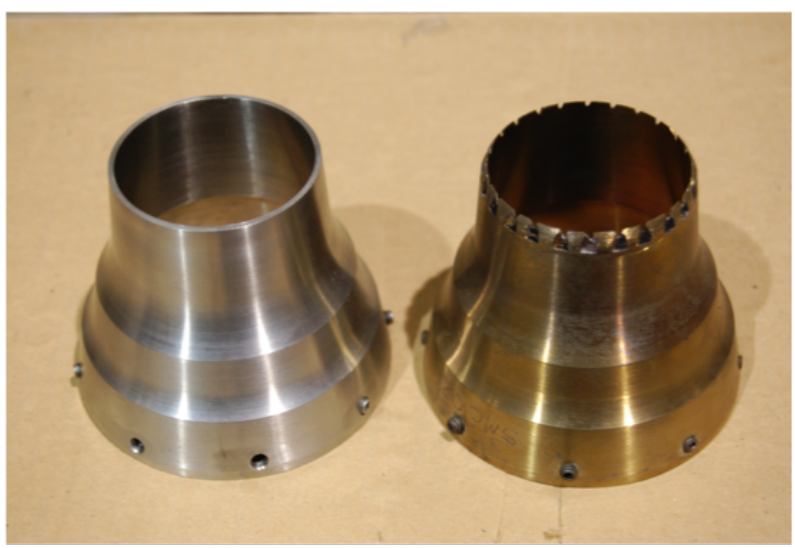

Figure 2. Nozzles: smc000 on the left, smc021 on the right.

To assess shock-containing jet noise prediction models, the data were collected using the smc021 nozzle operated at the 24 conditions listed in Table 1. The operating conditions are grouped according to constant total temperatures. However, the operating condition parameters were recorded at the time the acoustic 
Table 1. Test conditions for a convergent nozzle designated smc021 grouped according to total temperature.

\begin{tabular}{|c|c|c|c|c|c|c|c|c|c|}
\hline $\mathrm{Rdg}$ & $T_{t} / T_{\infty}$ & $\mathrm{NPR}$ & $M_{j}$ & $V_{j} / c_{\infty}$ & $\beta$ & $\gamma_{j}$ & $T_{\infty}(\mathrm{K})$ & $p_{\infty}(\mathrm{Pa})$ & $c_{\infty}(\mathrm{m} / \mathrm{s})$ \\
\hline 2079 & 1.01 & 2.005 & 1.049 & 0.954 & 0.315 & 1.4000 & 279.4 & 97789 & 335.04 \\
2080 & 1.01 & 2.358 & 1.178 & 1.047 & 0.623 & 1.4000 & 279.2 & 97783 & 334.92 \\
2081 & 1.01 & 3.147 & 1.392 & 1.186 & 0.969 & 1.4000 & 279.2 & 97788 & 334.93 \\
2082 & 1.01 & 3.636 & 1.493 & 1.245 & 1.109 & 1.4000 & 279.2 & 97790 & 334.93 \\
2083 & 1.01 & 4.647 & 1.660 & 1.338 & 1.325 & 1.4000 & 279.2 & 97796 & 334.89 \\
2085 & 1.01 & 5.708 & 1.796 & 1.406 & 1.491 & 1.4000 & 279.1 & 97794 & 334.87 \\
\hline 2088 & 1.77 & 2.004 & 1.050 & 1.264 & 0.319 & 1.3951 & 280.1 & 97814 & 335.44 \\
2089 & 1.77 & 2.365 & 1.182 & 1.388 & 0.630 & 1.3963 & 280.2 & 97817 & 335.52 \\
2090 & 1.76 & 3.143 & 1.392 & 1.568 & 0.968 & 1.3978 & 280.2 & 97826 & 335.49 \\
2091 & 1.76 & 3.627 & 1.492 & 1.647 & 1.108 & 1.3983 & 280.2 & 97831 & 335.50 \\
2092 & 1.77 & 4.644 & 1.660 & 1.775 & 1.325 & 1.3990 & 280.0 & 97826 & 335.37 \\
2093 & 1.76 & 5.674 & 1.792 & 1.858 & 1.487 & 1.3994 & 279.8 & 97814 & 335.30 \\
\hline 2100 & 2.16 & 1.989 & 1.045 & 1.390 & 0.305 & 1.3872 & 279.9 & 97851 & 335.34 \\
2098 & 2.16 & 2.356 & 1.181 & 1.533 & 0.628 & 1.3896 & 279.9 & 97842 & 335.34 \\
2097 & 2.16 & 3.130 & 1.390 & 1.734 & 0.966 & 1.3929 & 279.8 & 97837 & 335.25 \\
2096 & 2.16 & 3.629 & 1.494 & 1.828 & 1.109 & 1.3942 & 279.6 & 97839 & 335.18 \\
2095 & 2.16 & 4.638 & 1.659 & 1.959 & 1.324 & 1.3961 & 279.6 & 97825 & 335.16 \\
2094 & 2.16 & 5.685 & 1.794 & 2.056 & 1.489 & 1.3973 & 279.7 & 97830 & 335.23 \\
\hline 2102 & 2.66 & 1.987 & 1.048 & 1.542 & 0.314 & 1.3736 & 280.2 & 97865 & 335.54 \\
2103 & 2.65 & 2.327 & 1.175 & 1.691 & 0.617 & 1.3769 & 280.3 & 97857 & 335.58 \\
2104 & 2.66 & 3.120 & 1.391 & 1.926 & 0.967 & 1.3823 & 280.3 & 97859 & 335.59 \\
2105 & 2.65 & 3.597 & 1.490 & 2.020 & 1.105 & 1.3849 & 280.4 & 97864 & 335.61 \\
2106 & 2.64 & 4.630 & 1.660 & 2.168 & 1.325 & 1.3889 & 280.4 & 97857 & 335.61 \\
2107 & 2.65 & 5.638 & 1.789 & 2.276 & 1.484 & 1.3913 & 280.3 & 97854 & 335.58 \\
\hline
\end{tabular}

data were measured, hence, the numbers in the table reflect the slight variations in conditions that occurred during the testing. The table column headings are given as follows:

$\mathrm{Rdg}$ - designates the experimental reading number used to label the various operating conditions. $T_{t} / T_{\infty}$ - the nozzle flow total temperature to ambient temperature ratio.

NPR - the nozzle pressure ratio defined as the nozzle flow total pressure divided by the ambient pressure.

$\mathrm{M}_{j}$ - the fully expanded jet Mach number computed using the equation

$$
\mathrm{M}_{j}=\left[\left(\frac{2}{\gamma_{j}-1}\right)\left(\mathrm{NPR}^{\frac{\gamma_{j}-1}{\gamma_{j}}}-1\right)\right]^{\frac{1}{2}}
$$

$V_{j} / c_{\infty}$ - the acoustic Mach number is the ratio of the fully expanded jet velocity to the ambient speed of sound. The fully expanded jet velocity is computed from $\mathrm{M}_{j}$ using the fully expanded speed of sound

$$
c_{j}=\sqrt{\gamma_{j} R T_{j}}
$$

and the fully expanded temperature

$$
T_{j}=\frac{T_{t}}{1+\frac{\gamma_{j}-1}{2} \mathrm{M}_{j}^{2}}
$$


$\gamma_{j}$ - the ratio of specific heats at the fully expanded jet conditions. It is computed following the procedure given in the Appendix A.

$\beta$ - the shock noise parameter

$$
\beta=\sqrt{\mathrm{M}_{j}^{2}-1}
$$

$T_{\infty}$ - the ambient temperature in degrees Kelvin.

$p_{\infty}$ - the ambient pressure in Pascals.

$c_{\infty}$ - the ambient speed of sound in meters per second computed from the equation

$$
c_{\infty}=\sqrt{\gamma R T_{\infty}}
$$

where $\gamma=1.4$ and $R=286.959 \mathrm{~m}^{2} /\left(\mathrm{s}^{2} \mathrm{~K}\right)$.

\section{Description of Measured Data and Analysis}

The measurements of the noise radiated from the jet were made by 24 microphones. These microphones were located on an arc 50 nozzle exit diameters from the center of the nozzle exit area and placed at 24 equally-spaced angles. The angles were from 50 to 165 degrees as measured from the upstream inlet centerline to the nozzle.

As described in Bridges et al. ${ }^{11}$ and in Khavaran \& Bridges,${ }^{9}$ the time histories for the microphone signals were processed using the finite Fourier transform with suitable averaging and scaling to obtain narrow band spectral data with amplitude levels adjusted to report results at a radius of 100 nozzle exit diameters. The atmospheric attenuation inherent in the measured data was removed resulting in lossless spectra. These spectra contained 8193 points at equally spaced intervals of about $12 \mathrm{~Hz}$. The spectral amplitudes were normalized by the frequency interval to obtain a power spectral density. Follow-on processing generated $1 / 12$-octave and $1 / 3$-octave spectra as desired.

Given that only the total radiated jet noise was measured, Khavaran \& Bridges ${ }^{9,10}$ developed scaling laws that attempt to separate the total jet noise into its mixing noise and shock-associated noise components. They also discuss the phenomenon of mixing noise amplification resulting from the presence of any shockrelated screech tones. This additional noise could be considered to be part of the mixing noise component or the shock-associated noise component. Dahl ${ }^{2}$ showed that the spectra predicted from models for supersonic jet mixing noise were closer in comparison to the mixing noise component spectra with amplification noise. Hence, the shock-associated noise component spectra used in this study contained no amplification noise.

The results of the spectral component separation for the Table 1 conditions labeled 2090 and 2095 are shown in Figure 3 for measurements at 50, 90, and 120 degree inlet angles. The plots show 1/3-octave lossless spectra as a function of the Strouhal number $f D / V_{j}$, where, in this case, $f$ is the $1 / 3$-octave center frequency, $D$ is the nozzle exit diameter, and $V_{j}$ is the fully expanded jet velocity. Mixing noise can be seen to dominate at the lower frequencies and become a larger portion of the spectrum as the inlet angle moves toward downstream. Conversely, the broadband shock-associated noise dominates at the higher frequencies and at the upstream angles. The process of separating jet noise spectral components involves using scaling laws and interpolations that contain some inaccuracies. One example is shown in Figure 3f where shock noise is low relative to the total noise at the downstream angle. The separation method inaccuracies result in the mixing noise spectrum having some levels higher than the total noise spectrum levels. Figure 3 also shows the predicted spectra from the SAE broadband shock-associated noise model that is given next.

\section{Description of Prediction Model}

Supersonic jet flows from convergent nozzles are imperfectly expanded, creating shocks in the flow. The turbulence normally created by jet flows interacts with the shock structure producing a noise source in addition to that produced by turbulent mixing. This source may emit tones, known as screech, and a wide band of noise called broadband shock-associated noise. This latter noise is of main interest here. Though considered a broadband noise, shock-associated noise has a characteristic spectrum with a fundamental peak and has spectral levels that vary with the inlet angle. It is also most dominant at angles upstream of the nozzle exit. A prediction model for shock-associated noise was first proposed by Harper-Bourne \& Fisher. ${ }^{12}$ The 


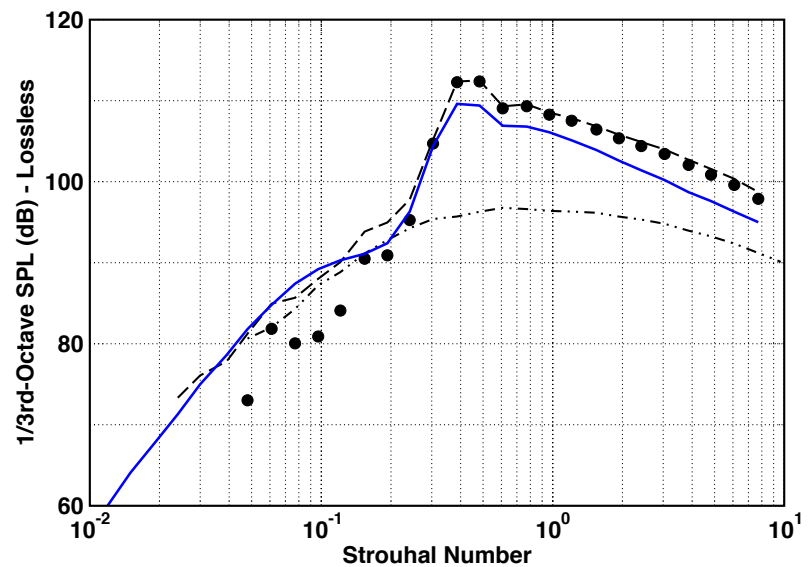

(a) $M_{j}=1.392, T_{t} / T_{\infty}=1.76, \beta=0.968, \theta=50$

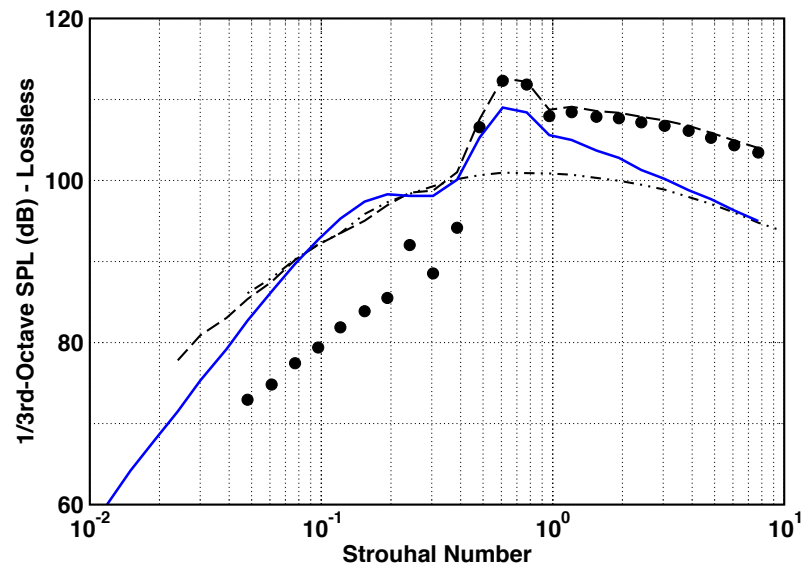

(c) $M_{j}=1.392, T_{t} / T_{\infty}=1.76, \beta=0.968, \theta=90$

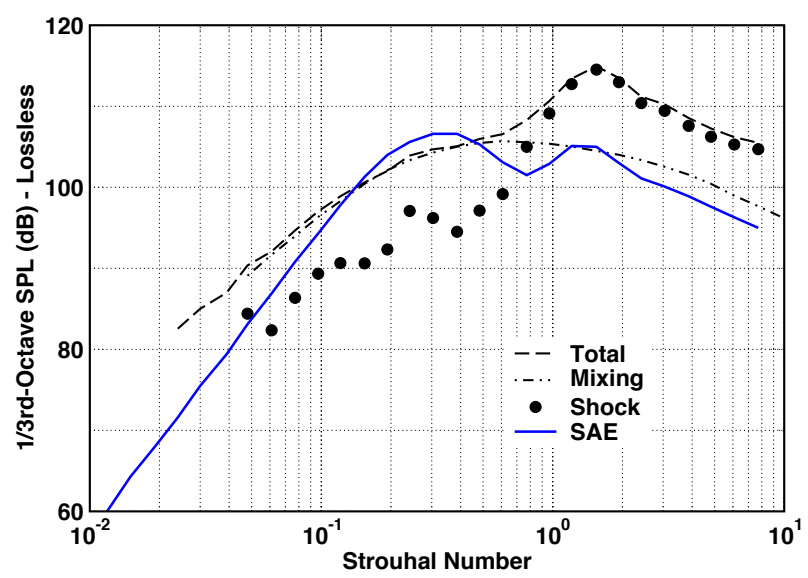

(e) $M_{j}=1.392, T_{t} / T_{\infty}=1.76, \beta=0.968, \theta=120$

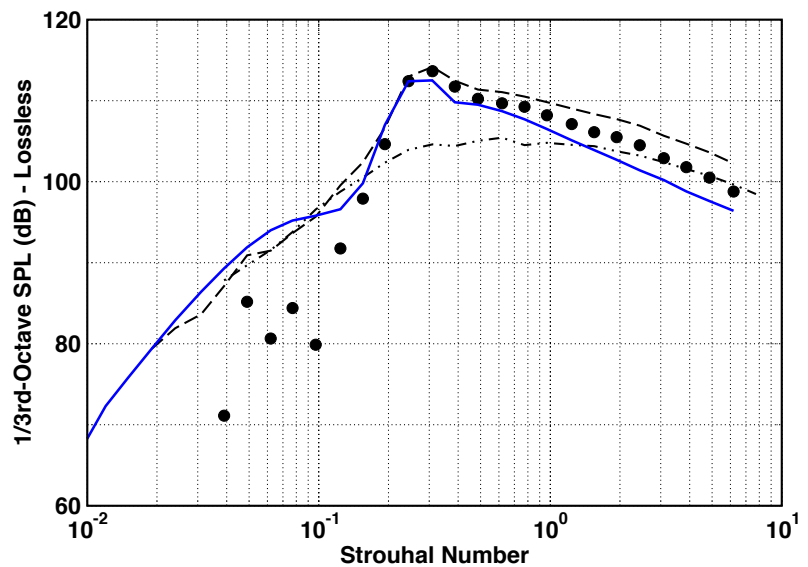

(b) $M_{j}=1.659, T_{t} / T_{\infty}=2.16, \beta=1.324, \theta=50$

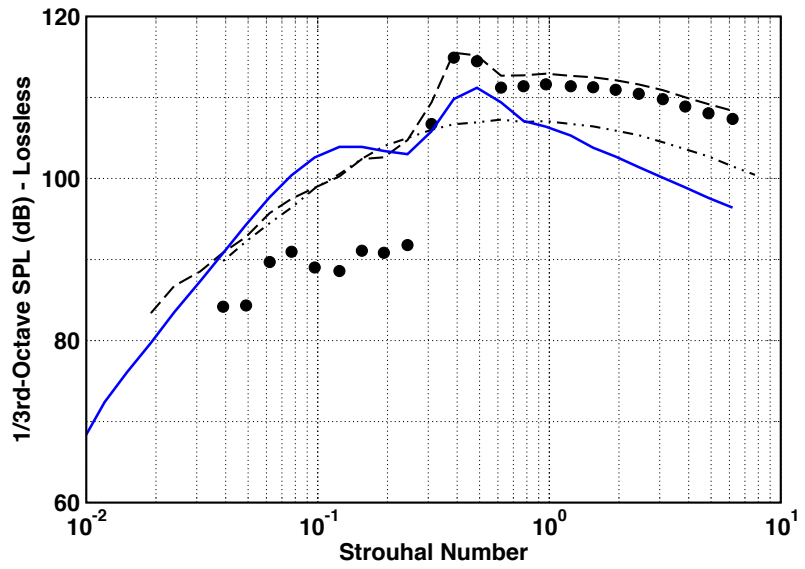

(d) $M_{j}=1.659, T_{t} / T_{\infty}=2.16, \beta=1.324, \theta=90$

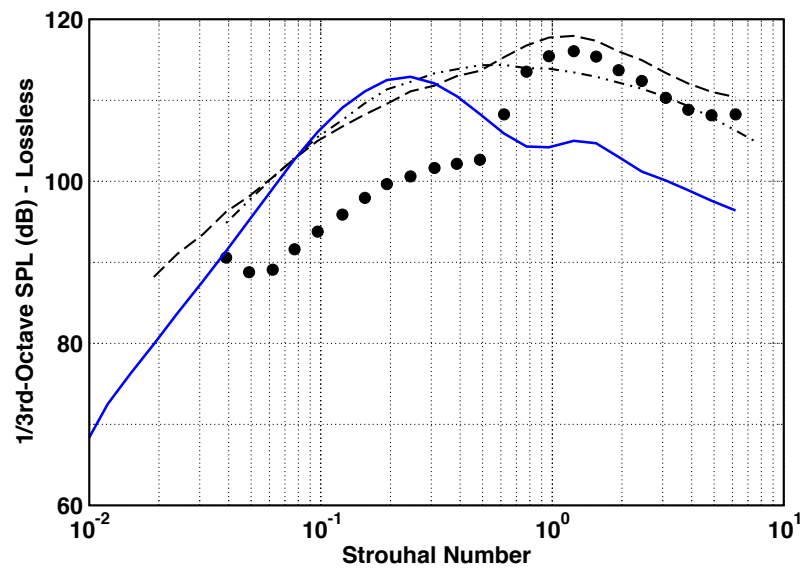

(f) $M_{j}=1.659, T_{t} / T_{\infty}=2.16, \beta=1.324, \theta=120$

Figure 3. 1/3-Octave spectra of the total, mixing component, and shock component noise for measured data from two jets with shocks at 50, 90, and 120 degree inlet angles and distance 100 $D$. The predictions from the original SAE broadband shock-associated noise model are shown for comparison. 
model is discussed further and compared to measured data in Balsa et al. ${ }^{13}$ and subsequently documented in SAE ARP 876E. ${ }^{3}$ The model was eventually incorporated into NASA's Aircraft Noise Prediction Program $(\mathrm{ANOPP})^{4}$ as the SAESHK module. After the equation for the far field pressure spectrum is integrated to obtain the sound pressure spectrum in 1/3-octave bands, as described by Balsa et al., ${ }^{13}$ the equation for the far-field mean-square acoustic pressure $\left\langle p^{2}\right\rangle$ in each band can be expressed as

$$
\left\langle p^{2}\right\rangle=1.92 \times 10^{-3} \frac{D^{2}}{16 r^{2}} \frac{\beta^{\eta}\left(\rho_{\infty} c_{\infty}^{2}\right)^{2}}{\left[1-\mathrm{M}_{\infty} \cos \theta\right]^{4}} H(\sigma)\left[1+W\left(\sigma, \theta, V_{j}\right)\right]
$$

where the parts of the equation are described as follows:

$D$ - exit diameter of a converging nozzle in meters.

$\mathrm{r}$ - distance from nozzle exit to observer in meters.

$\beta$ - shock noise parameter defined in equation (4).

$\eta$ - exponent that is equal to 4 if $\beta \leq 1$ or if $\beta>1$, it equals 1 for $T_{t} / T_{\infty}<1.1$ or 2 for $T_{t} / T_{\infty} \geq 1.1$

$\rho_{\infty}-$ the ambient density in $\mathrm{kg} / \mathrm{m}^{3}$.

$\mathrm{M}_{\infty}$ - the ambient Mach number.

$\theta$ - polar angle starting from the inlet direction.

$\sigma$ - frequency parameter given by

$$
\sigma=2 \pi K_{0} \frac{f D}{c_{\infty}} \beta\left[1-\mathrm{M}_{\infty} \cos \theta\right]
$$

$f$ - frequency in hertz.

$H$ - group source strength spectrum. For cold jets $T_{t} / T_{\infty}<1.1$, use $\log (H)-0.2$.

$W$ - shock cell interference function given by

$$
\begin{gathered}
W=\frac{4}{N_{s} b} \sum_{k=1}^{N_{s}-1}\left[K_{2} C(\sigma)\right]^{k^{2}} \sum_{m=0}^{N_{s}-(k+1)} \frac{\sin \left(b \sigma q_{k m} / 2\right)}{\sigma q_{k m}} \cos \left(\sigma q_{k m}\right) \\
q_{k m}=\left(\frac{K_{1}}{K_{0} C_{0}}\right) \frac{k}{\left(V_{j} / c_{\infty}\right)}\left[1-\epsilon\left(m+\frac{k+1}{2}\right)\right]\left(1+C_{0} \frac{V_{j}}{c_{\infty}} \cos \theta\right)
\end{gathered}
$$

$N_{s}$ - number of shocks, variable, typically set to 8 .

$b-1 / 3$-octave bandwidth constant, 0.23077 .

$C$ - correlation coefficient spectrum.

$K_{0}$ - average shock cell spacing, set to 1.1.

$K_{1}$ - first shock cell spacing constant, set to 1.31 .

$K_{2}$ - constant multiplying the correlation coefficient spectrum, set to 1.0.

$C_{0}$ - eddy convection velocity coefficient, set to 0.7 .

$\epsilon$ - due to variation in shock spacing, set to 0.06 .

\section{Results for SAE Model Predictions}

As mentioned above, Figure 3 contains the corresponding spectrum from the SAE model designed to predict broadband shock-associated noise. As can be seen in the comparisons at 50 degrees in Figure 3(a), the SAE model predicts the shock-associated noise quite well for the lower-speed jet. At the higher speed, Figure 3(b) shows the predicted spectrum compares favorably with the total noise spectrum especially at lower frequencies where mixing noise is dominant, but not quite as well at frequencies higher than the peak frequency where shock-associated noise dominates. At 90 degrees in Figure 3(c) and 3(d), the higher 
frequency predictions for the shock-associated noise are lower creating a larger difference between predicted and measured spectra. In addition, a low frequency hump develops in the predicted spectra that does not exist in the shock noise component spectra and does not represent the total noise spectral shape, either. This low frequency hump further develops at 120 degrees, as shown in Figure 3(e) and 3(f), and comes to dominate the spectra over that of the shock-associated noise related peak as $\beta$ and the jet temperature increase. There is little agreement between the SAE model predictions and the measured data at these conditions.

The major parts of the SAE model equation (6) are plotted in Figure 4. The plots show the shape of the $H$-spectrum multiplied by an amplitude coefficient when $W=0$ is used in equation (6). This spectrum is not a function of the inlet angle with no ambient flow and the peak shifts to lower frequencies as $\beta$ increases which follows from equation (7). The interference function $W$ modifies the shape of the $H$-spectrum. Since $W$ goes to zero at high frequencies, for plotting purposes the logarithm of $1+W$ added to 100 is displayed in the figure. The purpose of the interference function, in effect, is to suppress the group source strength $H$-spectrum at the lower frequencies and to accentuate the shock-noise peak. Clearly as the inlet angle increases and the jet becomes hotter, the group source strength spectrum becomes dominant and $W$ has less of an impact. The shock-associated noise is no longer predicted by the model.

\section{Toward a Revised Model}

A study was performed to seek improvements in the SAE broadband shock-associated noise prediction model using the data set given by Table 1 and the ability to separate the measured spectral data into component parts related to mixing noise and shock-associated noise. Tester et al. ${ }^{14}$ performed a similar type of study of this shock-associated noise model. They performed a parametric study on the frequency scaling, the correlation coefficient spectrum, the number of shocks, the eddy convection velocity constant, and the shock spacing constants. The conclusions based on comparing predicted spectra with total jet noise spectra where shock-associated noise dominates were to confirm the choice of parameter values given by Harper-Bourne \& Fisher ${ }^{12}$ and listed following equation (6) above. Modifications to the model were made in computing the overall levels where shock noise levels were extracted from the total noise and differences were noted between noise levels emitted by cold jets and levels emitted by jets that were heated. The approach here was to study the overall levels using the current approach for separating the shock-associated noise component from the measured total noise, conduct a sensitivity analysis of the model parameters, and to perform a least-squares fit of the model to the shock-associated noise component spectra of the measured data.

\section{VI.A. Overall Levels}

Equation (6) shows the results from the model development that the overall levels of shock-associated noise vary as $\beta$ to some power $\eta$. Figure 5 shows plots of the overall sound pressure levels (OASPL) determined for all the jet cases shown in Table 1 grouped by jet total temperature ratio. The data are the OASPL at three inlet angles less than or equal to 90 degrees. Figures $5(\mathrm{a})$ to $5(\mathrm{~d})$ use total noise OASPL data. In all cases for $\beta$ less than about 1.0, the data follow a $\beta^{4}$ sloped line except for the lowest $\beta$ cases of the heated jets where mixing noise becomes important at these upstream angles. For $\beta$ greater than 1.0, the cold jet data in Figure 5(a) follow a $\beta^{1}$ line and the hot jet data in Figures 5(b) to $5(\mathrm{~d})$ follow a $\beta^{2}$ line. These result are the same as those obtained by Tester et al. ${ }^{14}$ where shock noise levels separated from the total noise levels were used to perform the scaling.

The results for the OASPL scaling using the shock-associated noise component determined using the Khavaran \& Bridges ${ }^{10}$ method of component separation is shown in Figures 5(e) to 5(h). The cold jet results in Figure 5(e) are the same as in Figure 5(a) for the total noise OASPL. However for the heated jet OASPL determined from only the shock-associated noise component, the scaling results for $\eta$ deviate from those derived from using the total noise OASPL. At this point, it is possible to best fit a line through the data points that would result in non-integer values for $\eta$. Alternatively, we could follow Khavaran \& Bridges ${ }^{10}$ and allow $\eta$ to be a function of temperature and directivity angle. Most likely, the model is not that accurate that these small changes in $\eta$ would be significant in any particular prediction. Hence, we use integer values for $\eta$ to maintain the main variation in OASPL with $\beta$, as followed by Harper-Bourne \& Fisher, ${ }^{12}$ Balsa et al., ${ }^{13}$ and Tester et al. ${ }^{14}$ For $\beta$ less than about 1.0, the OASPL data follow a $\beta^{5}$ sloped 


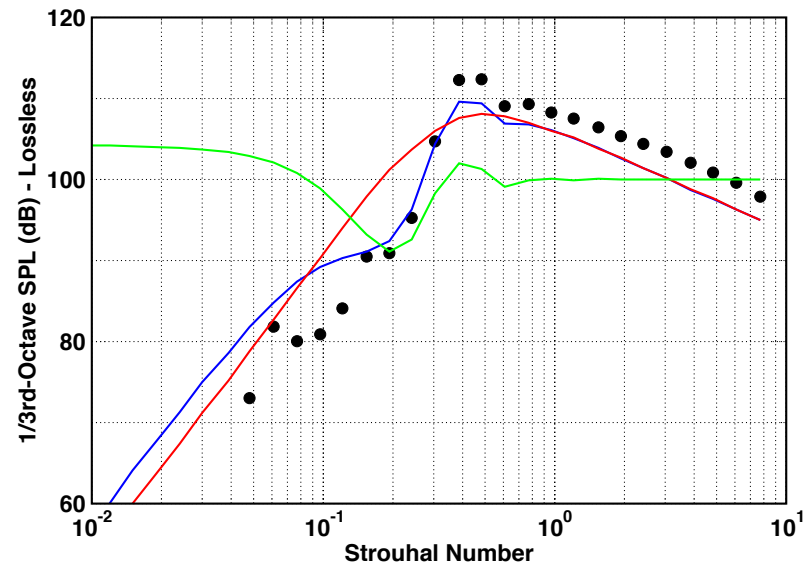

(a) $M_{j}=1.392, T_{t} / T_{\infty}=1.76, \beta=0.968, \theta=50$

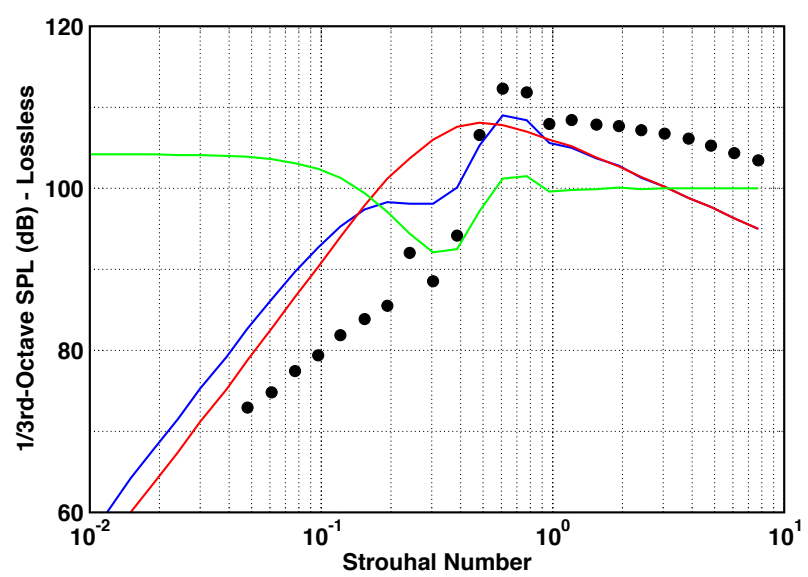

(c) $M_{j}=1.392, T_{t} / T_{\infty}=1.76, \beta=0.968, \theta=90$

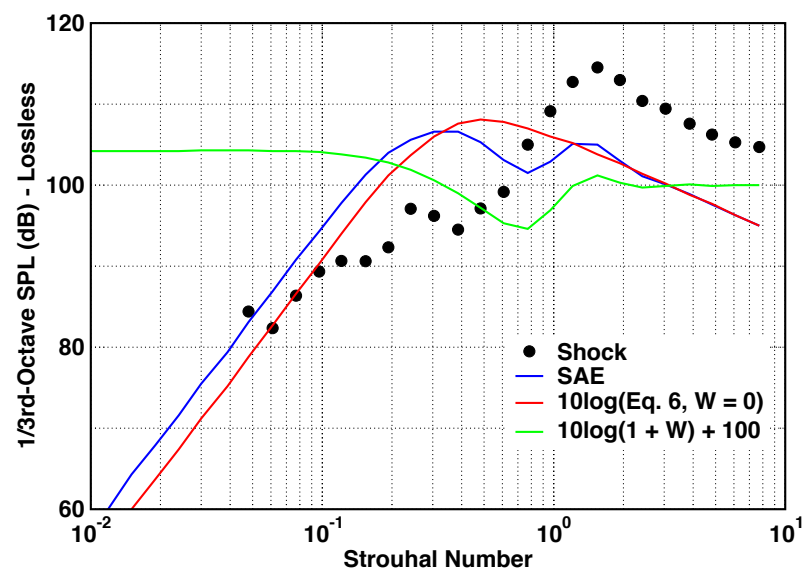

(e) $M_{j}=1.392, T_{t} / T_{\infty}=1.76, \beta=0.968, \theta=120$

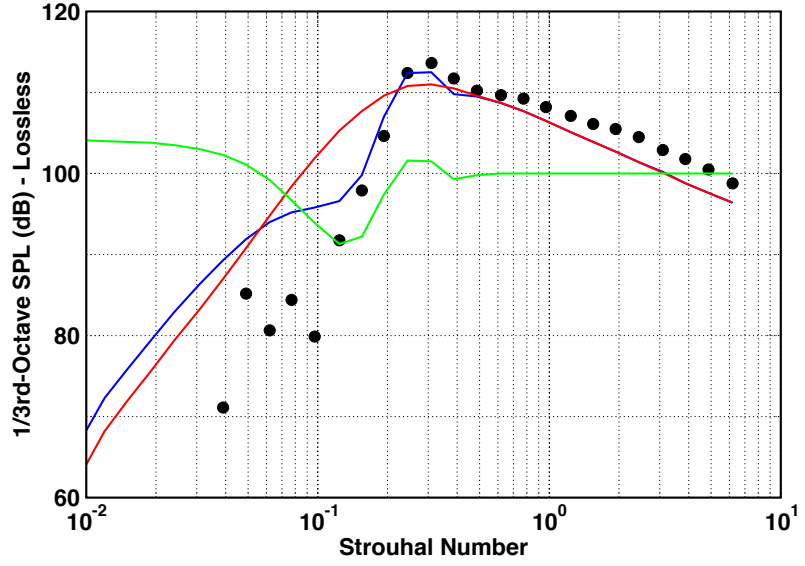

(b) $M_{j}=1.659, T_{t} / T_{\infty}=2.16, \beta=1.324, \theta=50$

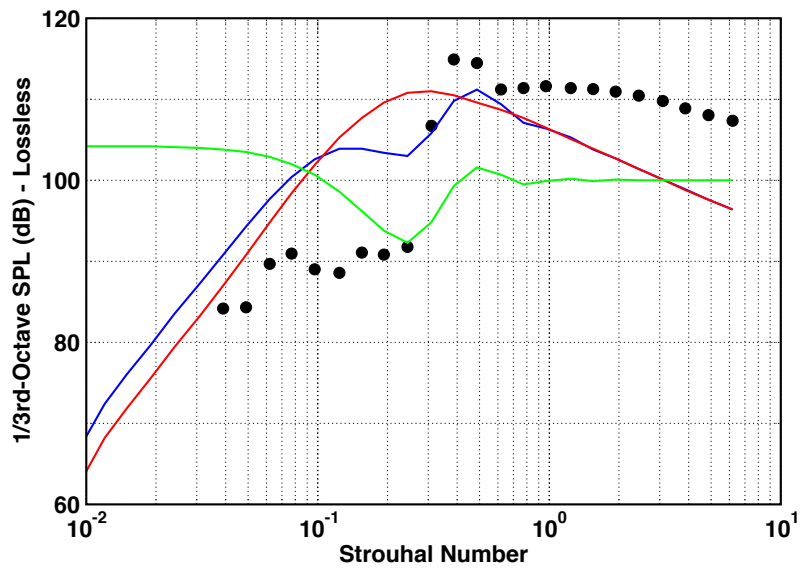

(d) $M_{j}=1.659, T_{t} / T_{\infty}=2.16, \beta=1.324, \theta=90$

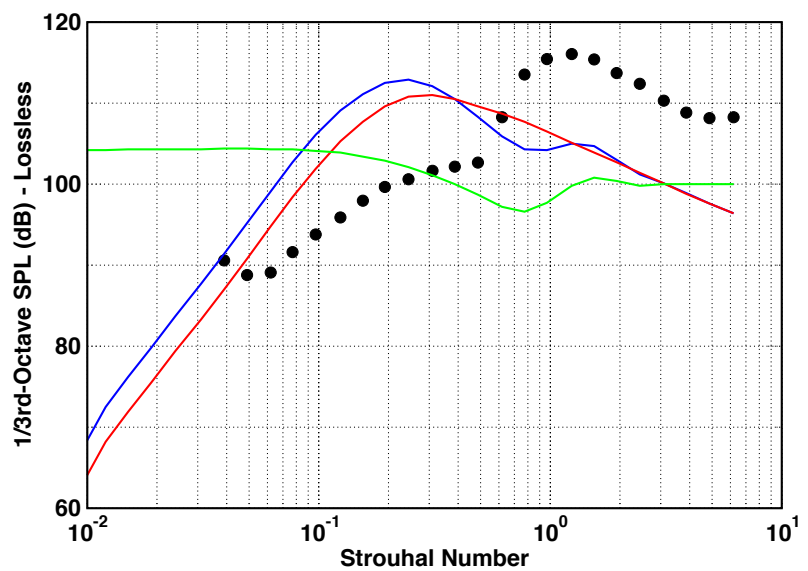

(f) $M_{j}=1.659, T_{t} / T_{\infty}=2.16, \beta=1.324, \theta=120$

Figure 4. 1/3-Octave spectra of the SAE shock noise prediction and its component parts compared to the shock noise component of measured data at 50, 90, and 120 degree inlet angles and distance $100 D$. 


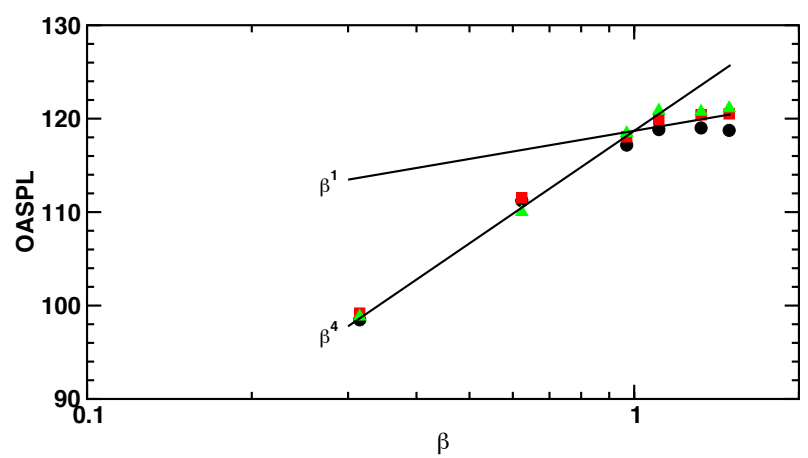

(a) Total Noise, $T_{t} / T_{\infty}=1.01$

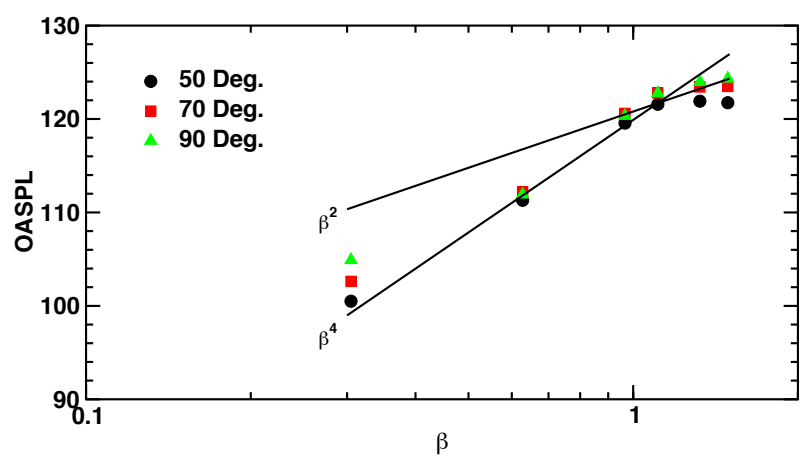

(c) Total Noise, $\mathrm{T}_{\mathrm{t}} / \mathrm{T}_{\infty}=2.16$

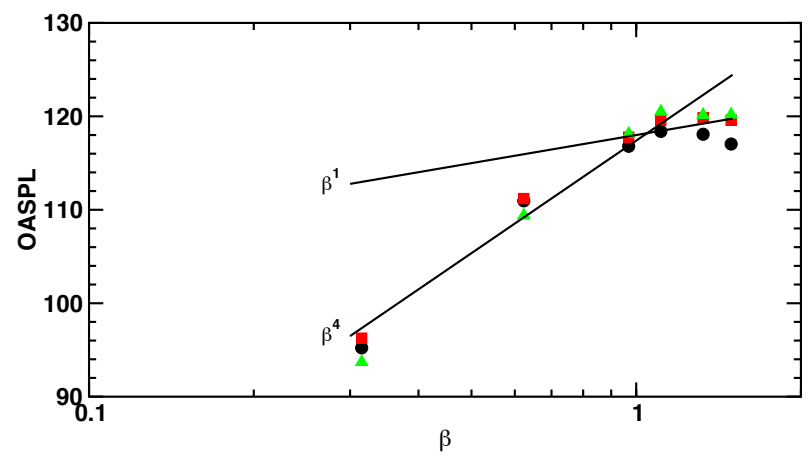

(e) Shock Noise, $\mathrm{T}_{\mathrm{t}} / \mathrm{T}_{\infty}=1.01$

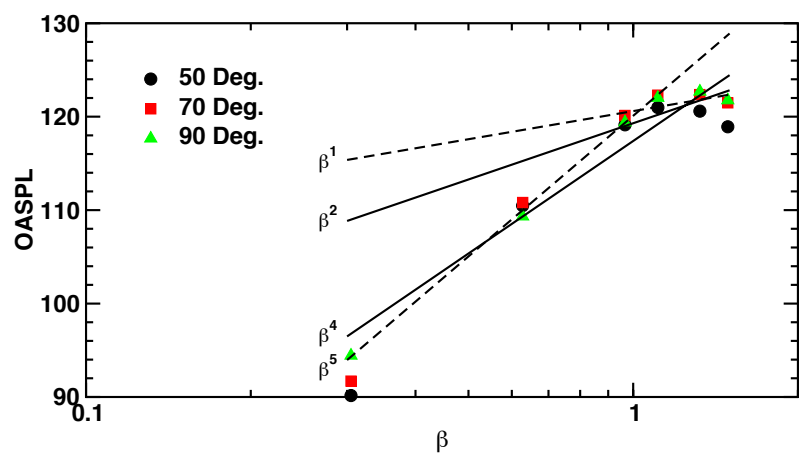

(g) Shock Noise, $\mathrm{T}_{\mathrm{t}} / \mathrm{T}_{\infty}=2.16$

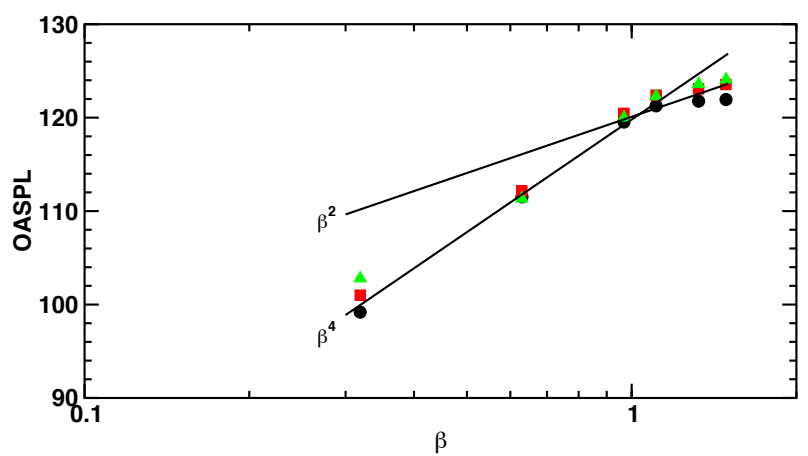

(b) Total Noise, $\mathrm{T}_{\mathrm{t}} / \mathrm{T}_{\infty}=1.77$

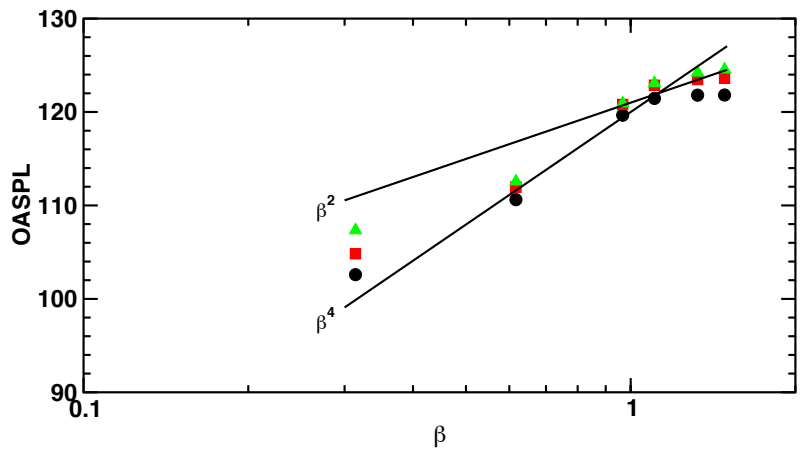

(d) Total Noise, $T_{t} / T_{\infty}=2.66$

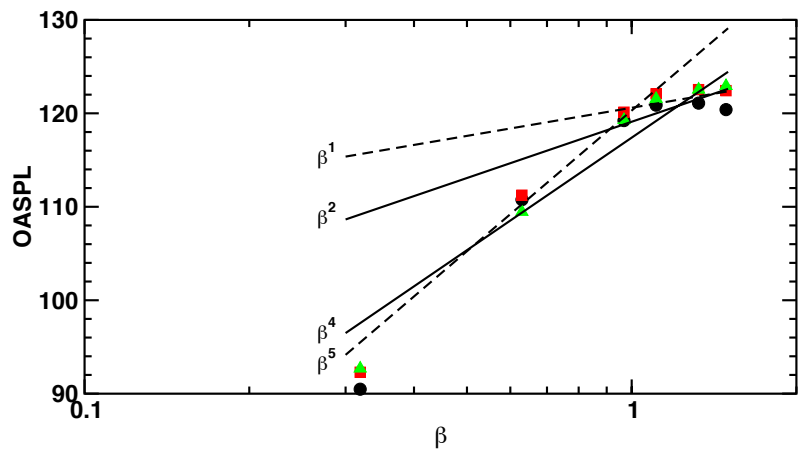

(f) Shock Noise, $T_{t} / T_{\infty}=1.77$

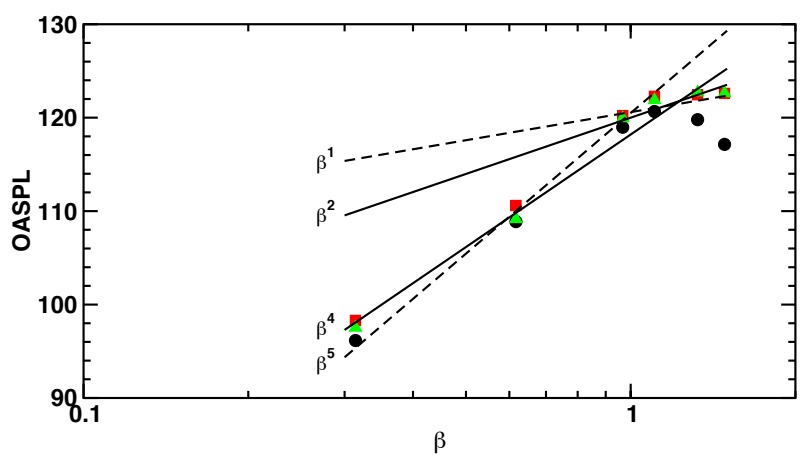

(h) Shock Noise, $\mathrm{T}_{\mathrm{t}} / \mathrm{T}_{\infty}=2.66$

Figure 5. Variations of overall sound pressure levels (OASPL) for the jets with operating conditions listed in Table 1 at three inlet angles as a function of the shock parameter $\beta$. Comparison of OASPL for the jet total noise to OASPL for the jet shock noise component only. Solid lines for variation in OASPL versus $\beta^{\eta}$ in the SAE model. Dashed lines are revised variations in shock noise component only OASPL versus $\beta^{\eta}$. 
line and for $\beta$ greater than 1.0, hot jet OASPL follow a $\beta^{1}$ line, the same as the cold jet data. The behavior of the shock noise only OASPL at 50 degrees and $\beta>1$ was noted but not studied further here.

\section{VI.B. Sensitivity Analysis}

A sensitivity analysis was conducted of the parameters that affect the behavior of the shock cell interference function $W$. Specifically, the following parameters were varied over the given values:

$$
\begin{aligned}
K_{0} & =0.6,0.9,[1.1], 1.2,1.3 \\
K_{1} & =1.01,1.21,[1.31], 1.41,1.61 \\
\epsilon & =0.04,0.05,[0.06], 0.07,0.08 \\
K_{2} & =0.8,0.9,[1.0], 1.1,1.2 \\
C_{0} & =0.5,0.6,[0.7], 0.8,0.9
\end{aligned}
$$

where the terms in brackets are the original model parameter values. Each parameter was varied one at a time while the others were held constant at their original value. The effects on $1+W$ are shown in Figure 6 for the jet condition labeled 2097 where the red dashed lines are the results for the minimum parameter values given in equation (10). The changes are systematic to the maximum parameter value results shown by the thick black dashed line. The measured data and the component parts of the original model as shown in Figure 4 are also shown in Figure 6. This helps to indicate what changes are required of the shock cell interference function $W$ that when it is included with the scaled $H$-spectrum $(W=0)$, the model predicted spectrum would be closer to the measured spectrum. The changes in the predicted spectrum as $W$ changes are not shown to reduce clutter in the plots.

The variations in $1+W$ due to changes in the shock spacing parameters $K_{0}, K_{1}$, and $\epsilon$ are shown in Figures 6(a) to 6(c). The largest changes are due to $K_{1}$ with lesser effects due to changes in $\epsilon$ and $K_{0}$. Note that changing $K_{1}$ affects the location of the shock-associated noise peak. As discussed in Tester et al. ${ }^{14}$ these changes could improve the spectrum prediction at some frequencies, but degrade the prediction at other frequencies. Adjusting these parameters to fit predicted spectra to measured data could lead to the shock spacing parameters having nonphysical values.

The $K_{2}$ parameter is intended to increase or decrease the correlation coefficient spectrum $C(\sigma)$ value without changing the shape of this spectrum. $C(\sigma)$ has the highest correlation values at the lower frequencies with decreasing values as the frequency increases. Using the documented values of $C(\sigma)$ as a baseline, ${ }^{3,4}$ $K_{2}$ is limited to a maximum value of 1.351 to insure that the correlation coefficient spectrum is less than or equal to 1.0. The results in Figure 6(d) shows that increasing $K_{2}$ would result in a slightly more rapid decrease in the lower frequency portion of the predicted spectrum.

Finally, Figure $6(\mathrm{e})$ shows that changes in the eddy convection velocity coefficient $C_{0}$ has the largest effect on $1+W$. It will be considered further separately.

\section{VI.C. Convection Velocity}

The results shown in Figure 6(e) indicate that changes in the convection velocity affect the behavior of $1+W$ in the prediction model. These changes are for a constant convection velocity at all frequencies. As with the shock spacing parameters, its adjustment could improve or degrade the predicted spectrum depending on the frequency. But unlike the shock spacing parameters which are fixed values that should be determined from flow measurements, the eddy convection velocity coefficient is known to be frequency and velocity dependent through the Strouhal number. ${ }^{15-17}$

To explore the effect of a Strouhal dependent convection velocity on the predicted shock-associated noise spectrum, the $C_{0}$ eddy convection velocity coefficient in equation (9) was considered to be a function of frequency. A least-squares fit of the predicted spectrum to the measured shock-associated noise component spectrum was performed where the $C_{0}$ 's at each frequency are the only parameters for each of 15 hot jet cases where $\mathrm{M}_{j}>1.05$ and where the fit included data from eight inlet angles from 50 to 120 degrees. Using the velocity $V_{j}$ for each operating condition, the results for $C_{0}$ are plotted as a function of the Strouhal number in Figure 7. The Strouhal number range was limited to about 0.2 to 2.0 to cover the peak shock-associated noise. Even though the fit is done using far-field spectral data, the eddy convection velocity coefficient $C_{0}$ values tend to cluster along the lines given by Harper-Bourne ${ }^{15}$ and Morris \& Zaman ${ }^{16}$ for the Strouhal dependent convection velocity derived from flow measurements especially for Strouhal numbers less than 1.0 


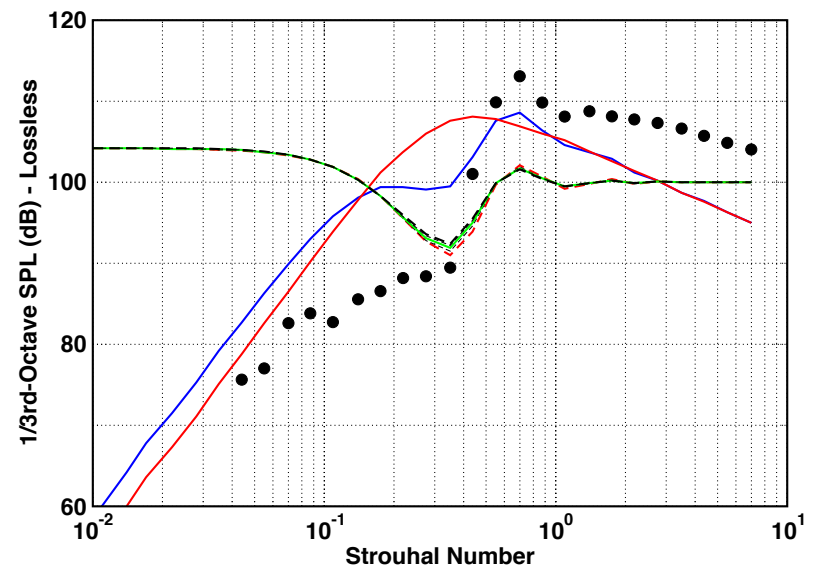

(a) Vary $K_{0}$, average shock cell spacing

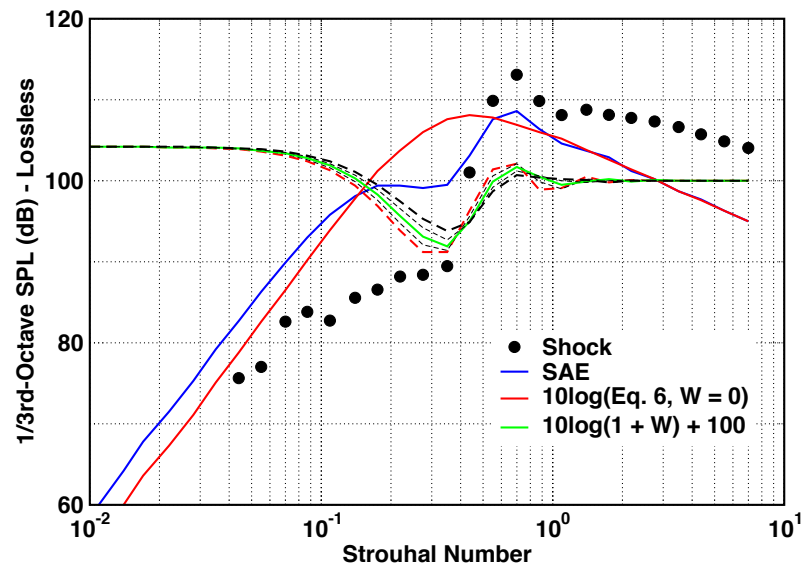

(c) Vary $\epsilon$, variation in shock spacing

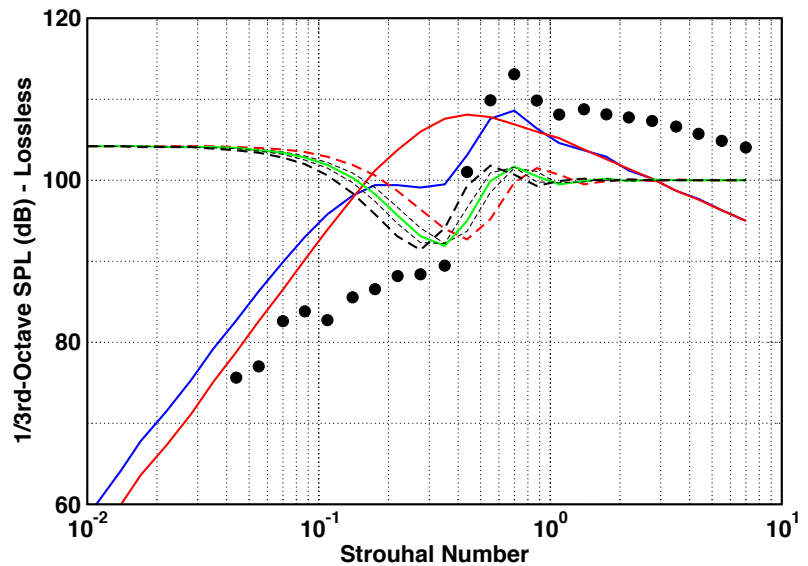

(b) Vary $K_{1}$, first shock cell spacing constant

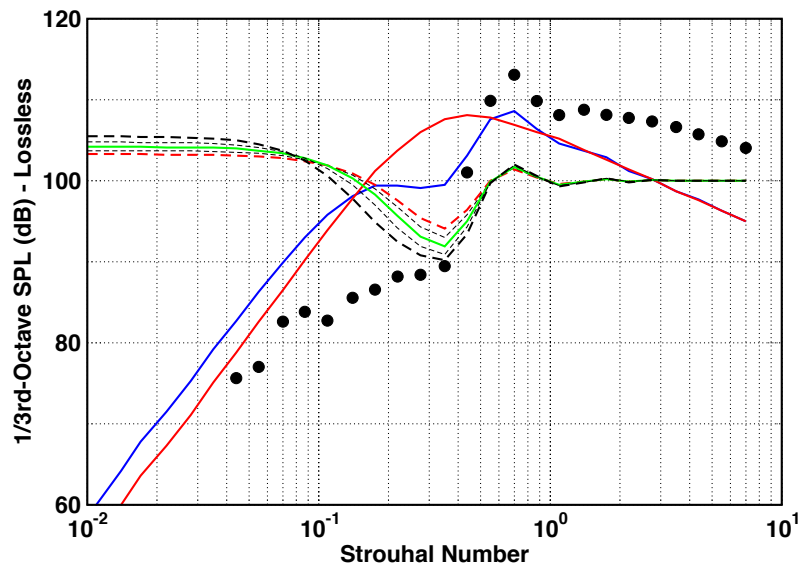

(d) Vary $K_{2}$, correlation coefficient spectrum multiplier

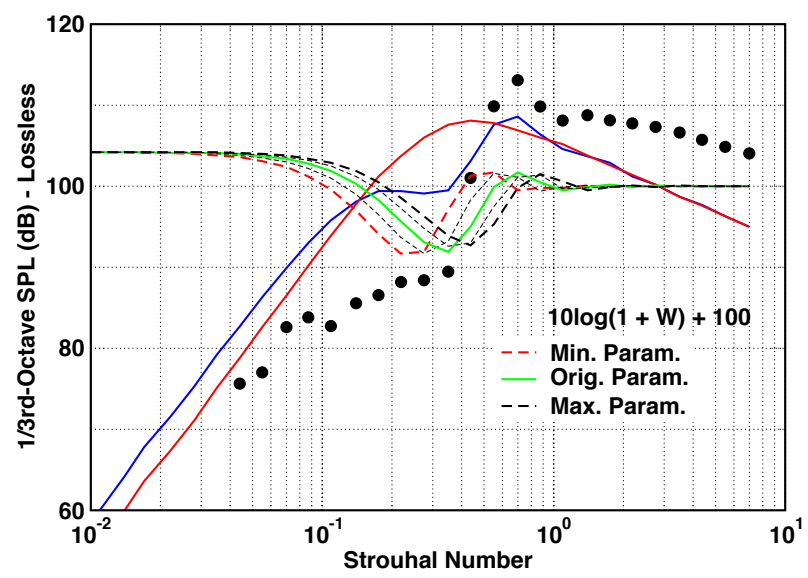

(e) Vary $C_{0}$, eddy convection velocity coefficient

Figure 6. 1/3-Octave spectra results from a sensitivity analysis of the parameters affecting the $1+W$ component of the SAE shock noise model. Jet condition 2097 at a 90 degree inlet angle and distance 100D. 


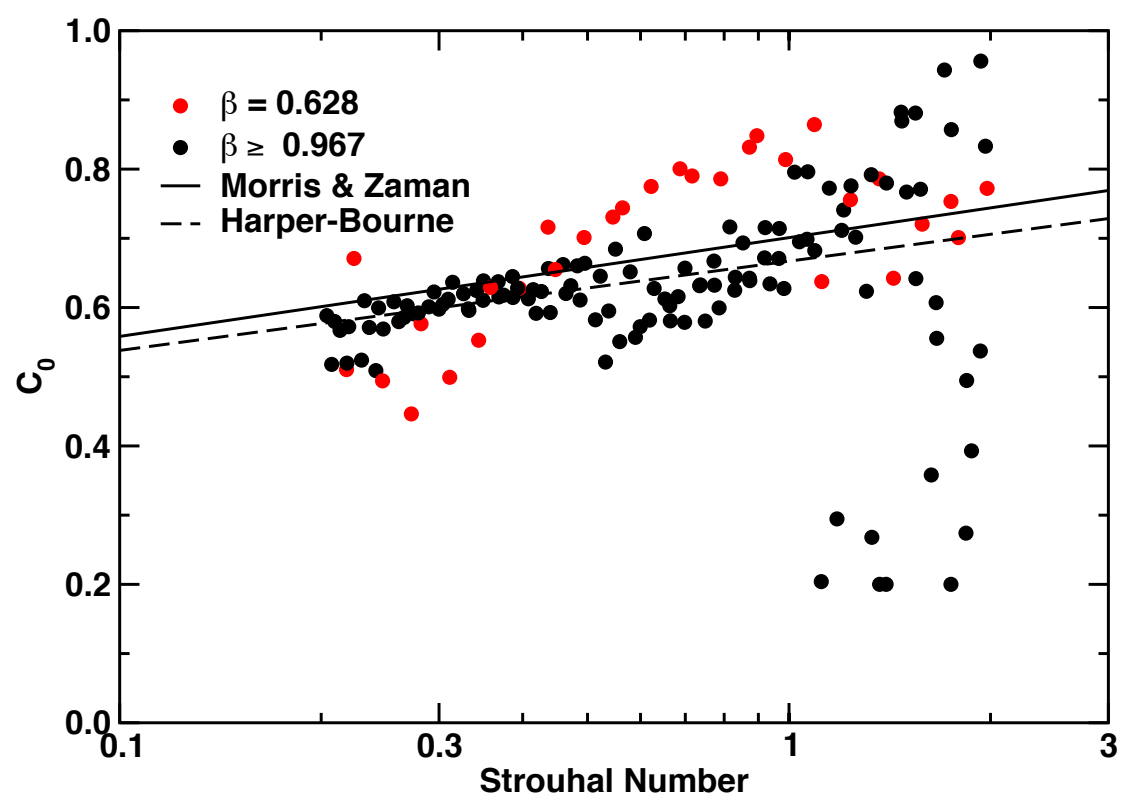

Figure 7. Scatter of convected velocity results from a least-squares fit of the SAE shock noise model using the shock noise component of measured far-field noise data. Lines are the results from measured flow field data.

and $\beta \geq 0.967$. In both of the previous measurement cases, low speed jets were used. Dahl ${ }^{17}$ later showed convection velocity results from a near $\mathrm{M}_{j}=1$ jet that followed these convection velocity lines. Hence, we replace the constant $C_{0}$ by the equation from Morris \& Zaman

$$
C_{0}\left(f, V_{j}\right)=0.062 \ln \left(\frac{f D}{V_{j}}\right)+0.701
$$

\section{VI.D. Group Source Strength Spectrum}

Of the parameters available to improve equation (6) to better predict the shock-associated noise component of the measured data sets, we are left with the group source strength spectrum $H(\sigma)$ and the correlation coefficient spectrum $C(\sigma)$ at each frequency. Attempts at adjusting both in a least-squares fit has not led to satisfactory results as the best fit values at each frequency had large variations from one frequency to the next and from one operating condition to the next. Hence, the current choice is to set $K_{2}=1.0$ and to use the original model values for $C(\sigma)$ as suggested by the findings of Tester et al. ${ }^{14}$

Using equation (11) for the eddy convection velocity coefficient and the revised set of $\eta$ exponent values for hot jets given in Figures 5(f) to 5(h), a least-squares fit of the predicted spectrum to the measurement derived shock-associated noise component spectrum was performed to obtain $H(\sigma)$. The data was from the 20 jet cases shown in Table 1 where $\mathrm{M}_{j}>1.05$ including five cold jet operating conditions and the remainder were hot jets. The spectral data came from three inlet angles, 50, 60, and 70 degrees, where shock-associated noise dominates at all operating conditions. The fit results for $H(\sigma)$ are shown in Figure $8($ a) for all the jet operating conditions. The original $H(\sigma)$ spectrum is shown for comparison. ${ }^{3,4}$ The remaining five plots in Figure 8 show the same data at nominally fixed $\beta$ values representative of those shown in Table 1 . The findings are as follows:

- The fit results for $H(\sigma)$ at frequencies less than the peak frequency have larger variations due to the shock-associated noise component spectra containing oscillations and possible remnants of screech tones as can be seen in the shock noise component spectra in Figure 3.

- $H(\sigma)$ appears to be independent of jet temperature for hot jets at a fixed $\beta$ as noted by the similar results at frequencies higher than the peak frequency.

- The cold jet results for $H(\sigma)$ were found to be about $3 \mathrm{~dB}$ lower than the hot jet results for $H(\sigma)$. The cold jet $H(\sigma)$ values in Figure 8 are plotted as $\log (H)+0.3$. This differs from the current SAE model where cold jet levels differ from hot jet levels by $2 \mathrm{~dB} .^{3,4}$ 


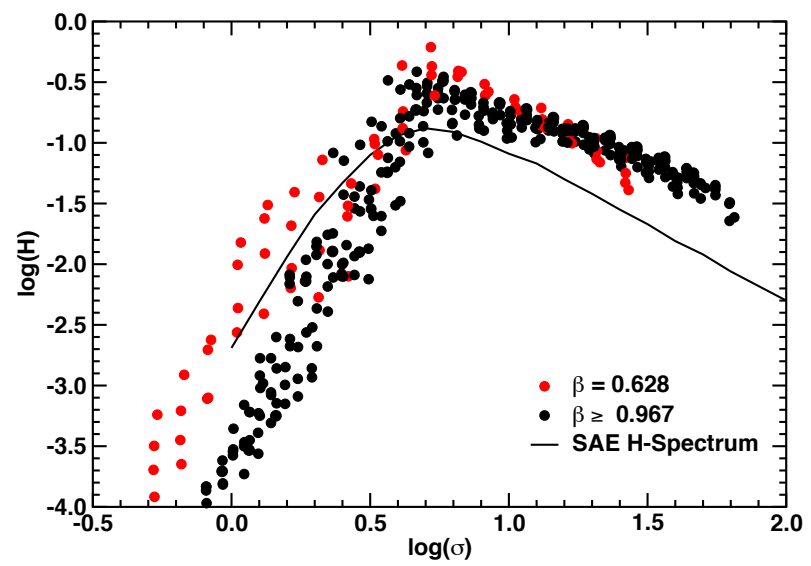

(a) All

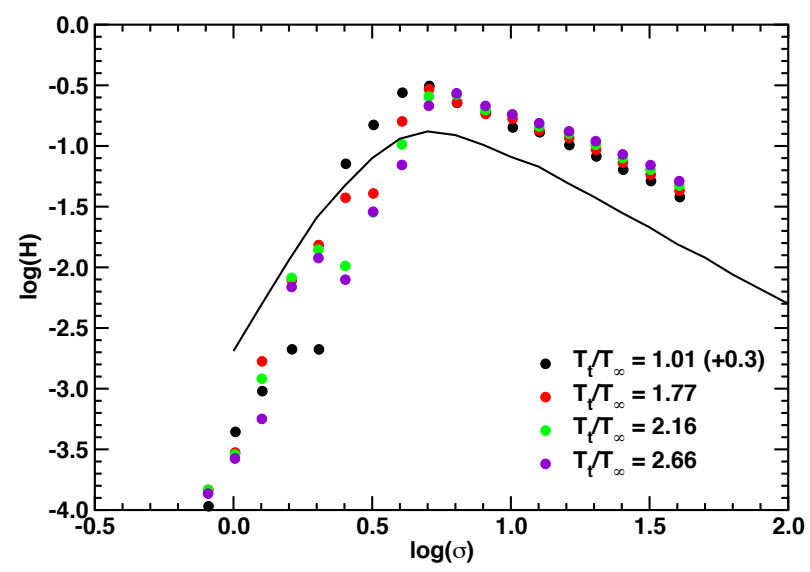

(c) $\beta=0.967$

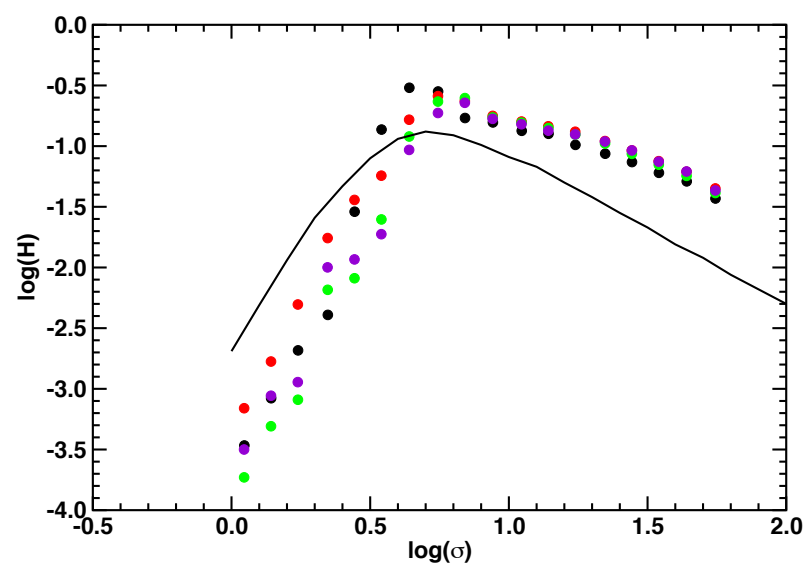

(e) $\beta=1.325$

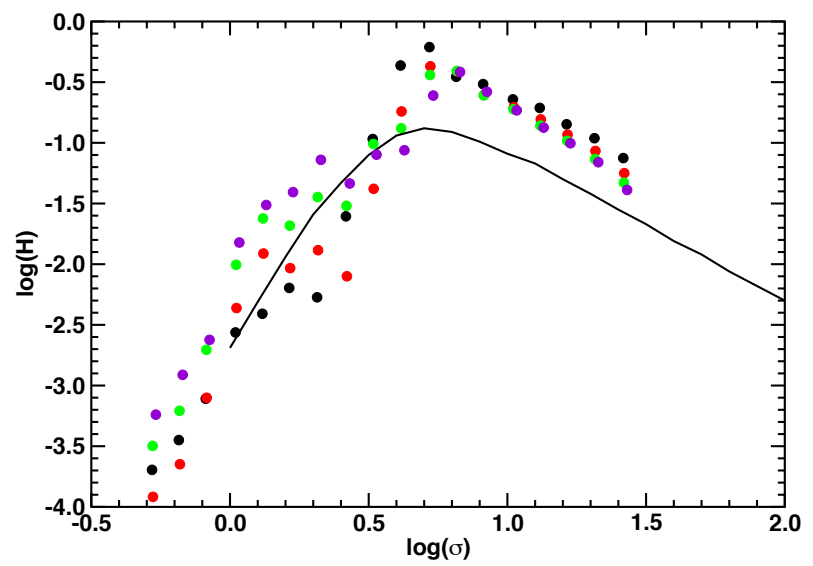

(b) $\beta=0.628$

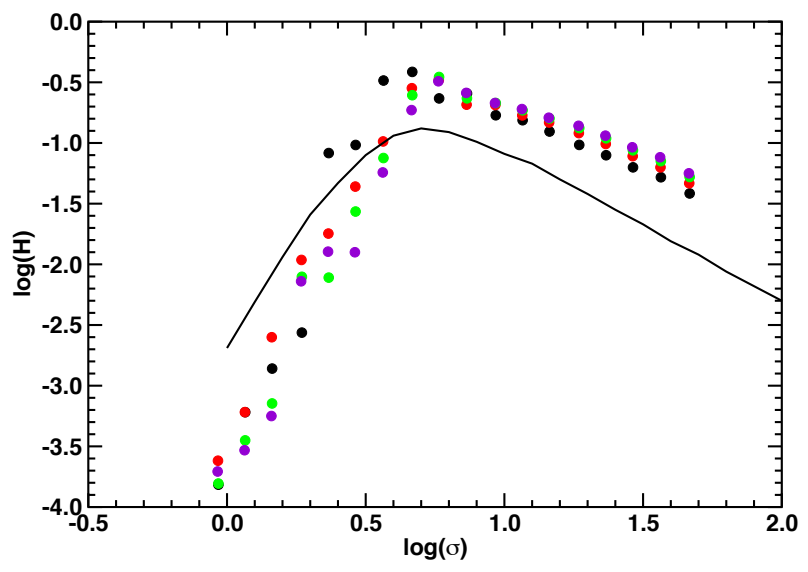

(d) $\beta=1.105$

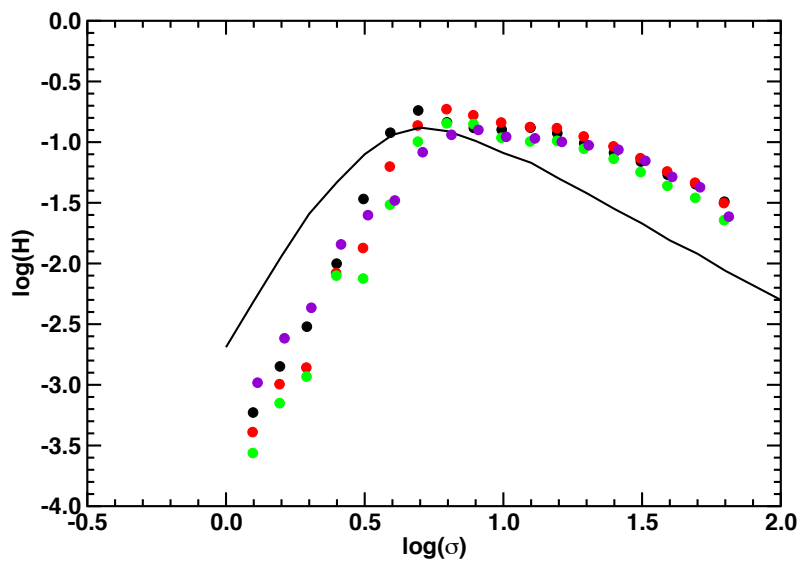

(f) $\beta=1.487$

Figure 8. Results for the group source strength spectrum $H$ from a least-squares fit of the SAE shock noise model using the shock noise component of measured far-field noise data. Lines are the original SAE model $H$-spectrum. 
- The issue with the oscillation in the measured shock-associated noise component spectra at frequencies less than the peak frequency (mentioned above) are especially evident in the $\beta=0.628$ jet results, Figure 8(a) (red symbols). These lower frequency points are not considered to be representative of the lower frequency decrease in shock-associated noise. Removing these points shows that the remaining $H(\sigma)$ fit results have a definite clustering about a new spectrum shape. Furthermore, the removing of the $\beta=0.628$ fit points does not have a significant effect on the peak and higher frequency definition of a new $H(\sigma)$ spectrum.

The objective is now to replace the SAE $H$-spectrum with a new spectrum based on the fit results for $H(\sigma)$ where $\beta \geq 0.967$. This was done using the empirical mode decomposition method and using the least-squares fit method.

\section{VI.D.1. $H(\sigma)$ from Empirical Mode Decomposition}

The cluster of $H(\sigma)$ fit data points shown in Figure 8(a) may be considered as a short duration signal with high frequency content riding on a definitive background trend. A method to extract this trend is called empirical mode decomposition. This method separates a data signal into a series of basis functions each containing a limited frequency range starting from a high frequency band and continuing down toward lower frequency bands until a residual of the signal is reached that contains no oscillating content. ${ }^{18}$ For our purposes, the residual of the series of data points put together from the $H(\sigma)$ fit points represents the basic trend or shape of the $H(\sigma)$ spectrum. Dahl ${ }^{17}$ described the process of empirical mode decomposition (EMD) that was used on this data. Given that the $H(\sigma)$ signal is made from overlapping spectral data points, the signal is highly irregular in its sampling. Since EMD was applied to this set of data points regardless of variable sampling rate (Hence, implicitly evenly spaced.), the resulting smooth residual curve contained jaggedness when plotted versus the actual $\log (\sigma)$ value for each data point. The solution to obtaining a smooth $\log (H)$ versus $\log (\sigma)$ curve was to pass the residual signal through a 15-point moving average filter and then resample it onto an evenly spaced grid in $\log (\sigma)$ using a 5-point Lagrange interpolating polynomial. To extend the curve beyond the high end of the data out to $\log (\sigma)=2.5$, a straight line was used based on a linear least-squares fit of the EMD spectrum between $\log (\sigma)=1.6$ to 1.72. The process of computing the EMD involves choosing stopping criteria that may lead to variations in results. A sampling process was employed to reduce the variation by averaging the results. After 200 samples, the averaged $H$-spectrum had a maximum uncertainty of \pm 0.005 . This averaged EMD-derived $H$-spectrum is shown in Figure 9 compared to the data points and the original SAE $H$-spectrum, and it is also tabulated in Table 5, Appendix B.

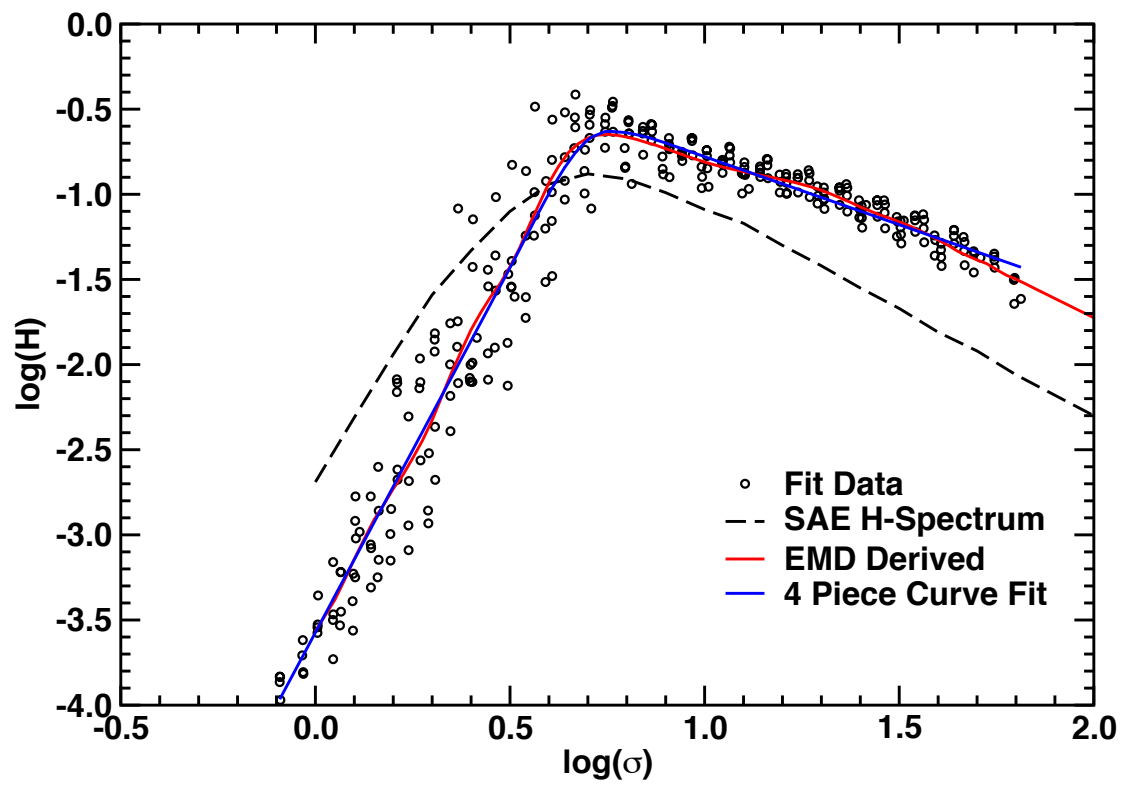

Figure 9. Single curve definitions for the $H$-spectrum derived from fit data. 


\section{VI.D.2. Equation for $H(\sigma)$ from the least-squares fit method}

The $H(\sigma)$ fit data points shown in Figure 9 also have a shape reminiscent of the shock-associated noise spectral shape proposed by Deneuville ${ }^{19}$ consisting of two sloping straight lines meeting at the peak of the spectrum. But instead of an abrupt change in slopes between two lines, it was desired to represent the smooth curvature at the peak that EMD showed was part of the residual trend of the spectrum. The solution was to connect the two straight lines with two lines governed by cubic equations. At the three interface points between the four lines, the value and its derivative were considered to be continuous. It turns out that a sensible least-squares fit is difficult to achieve if the location of the three interface points are included as fit parameters. Thus, the choice of the location of these three points was arbitrary.

Using $x=\log (\sigma)$ and $y=\log (H)$, the 4 line piecewise curve fit to the $H(\sigma)$ fit data is given by:

$$
\begin{aligned}
& x \leq 0.5 \\
& y=-1.431+4.284(x-0.5) \\
& 0.5<x \leq 0.75 \\
& y=-0.6307+0.01952(x-0.75)-21.13(x-0.75)^{2}-33.60(x-0.75)^{3} \\
& 0.75<x \leq 0.9 \\
& \quad y=-0.6307+0.01952(x-0.75)-4.052(x-0.75)^{2}+5.882(x-0.75)^{3} \\
& 0.9<x \\
& y=-0.6991-0.7989(x-0.9)
\end{aligned}
$$

where the maximum uncertainty in the fit of $y$ is \pm 0.1 . A plot of this spectrum is also shown in Figure 9. This spectrum result is very close to that obtained using EMD except at the highest frequencies. The extrapolation of the linear fit to frequencies higher than $\log (\sigma)=1.72$ will result in higher curve-fit spectrum levels than for the EMD-derived spectrum extrapolated levels.

\section{Revised Model Results}

The predicted spectra from the revised model are compared to the original SAE shock-associated noise prediction model. Using the same operating conditions and inlet angles as in Figure 3, the revised model shock-associated noise predictions are shown in Figure 10 for both the EMD-derived and the curve fit $H$ spectra. As expected from the closeness in the new $H$-spectrum shapes shown in Figure 9, the results in Figure 10 are nearly identical except near the extremes of high and low frequencies. The revised predictions more closely represent the shock-associated noise component spectra of the measured data at inlet angles less than or equal to 90 degrees. The lower frequency hump arising in the original SAE model spectra is no longer present. At the 120 degree angle, the revised model is also failing in the same manner as the original model even though the revised model is an improvement by lowering the levels at the lower frequencies and raising the levels at the higher frequencies. The group source strength spectrum still becomes dominant and the interference function is unable to cancel out the lower frequency hump and accentuate the shock noise peak sufficiently for better agreement with the measured data.

One consequence of using the new $H$-spectra shown in Figure 9 that are based on measured data from jets with higher $\beta$ values is that jets with lower $\beta$ values may have their shock-associated noise component spectra inaccurately predicted. In Figure $8(\mathrm{a})$, it is shown that the $\beta=0.628$ spectral data points are higher in level at the lower frequencies than the higher $\beta$ jet spectral data points. Thus, the revised model will underpredict the data at the lower frequencies. (The original SAE model has similar spectral characteristics as a function of $\beta$ as shown in the large set of comparisons between predicted and measured spectra in Dahl. ${ }^{2}$ ) However, the lower $\beta$ jets have similar levels to those of the higher $\beta$ jets at the peak frequency and higher. Hence, the higher frequencies should still be well predicted. This fact will be accounted for in computing the prediction errors.

The errors and uncertainties were computed for the original SAE model and the revised model shockassociated noise predictions at the 24 jet operating conditions listed in Table 1 . A measure of the error in 


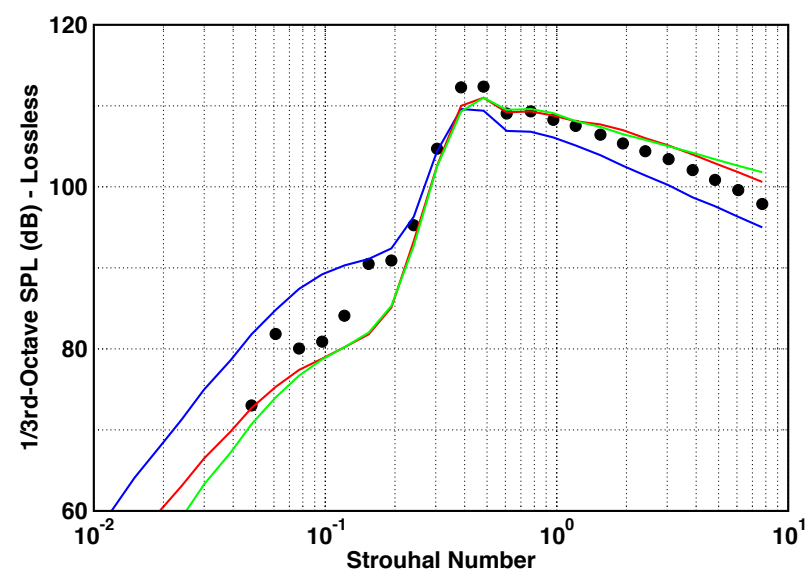

(a) $M_{j}=1.392, T_{t} / T_{\infty}=1.76, \beta=0.968, \theta=50$

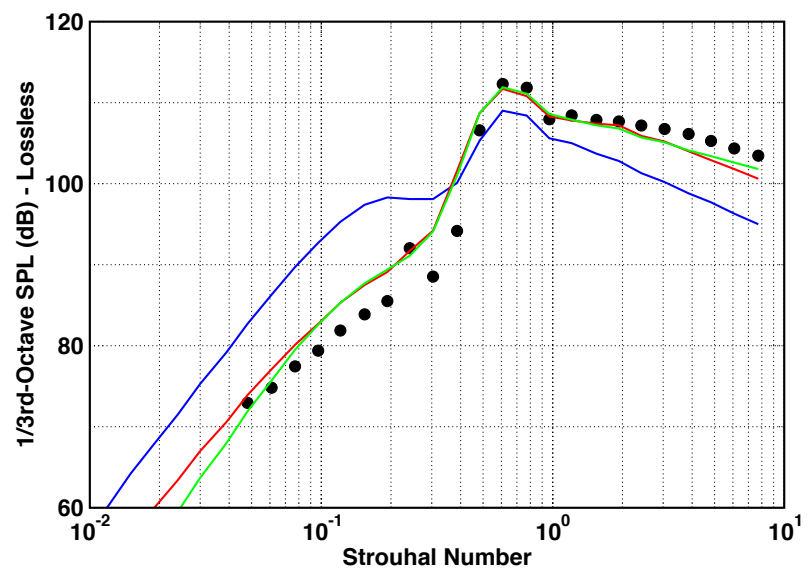

(c) $M_{j}=1.392, T_{t} / T_{\infty}=1.76, \beta=0.968, \theta=90$

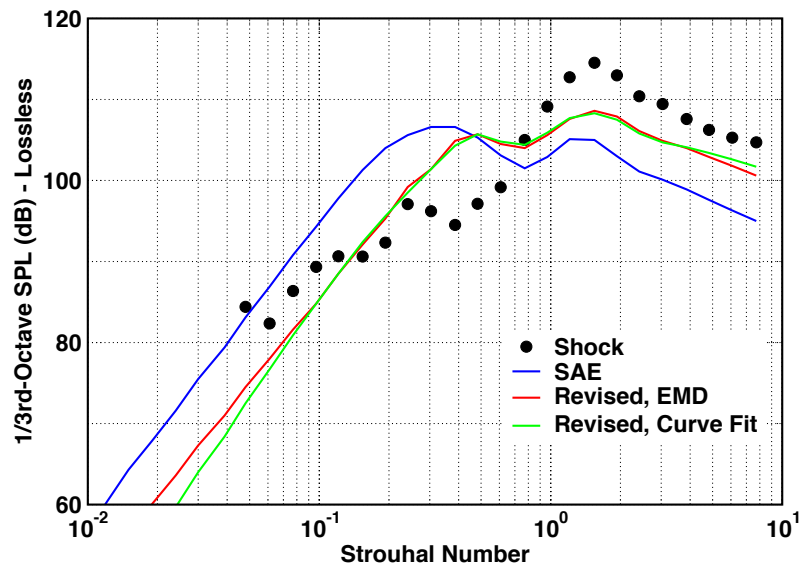

(e) $M_{j}=1.392, T_{t} / T_{\infty}=1.76, \beta=0.968, \theta=120$

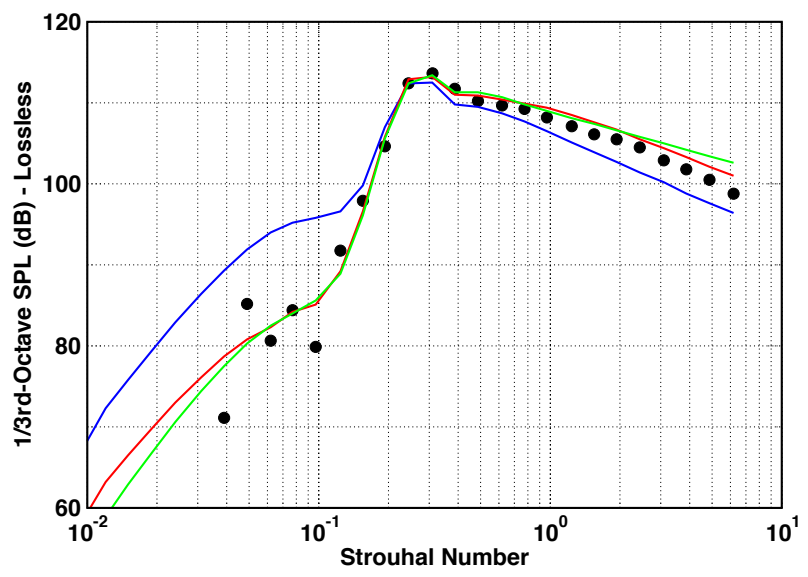

(b) $M_{j}=1.659, T_{t} / T_{\infty}=2.16, \beta=1.324, \theta=50$

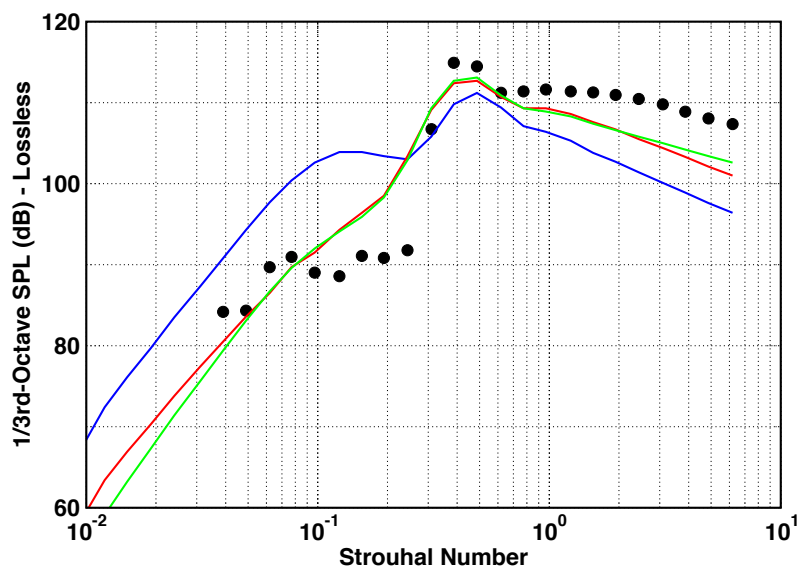

(d) $M_{j}=1.659, T_{t} / T_{\infty}=2.16, \beta=1.324, \theta=90$

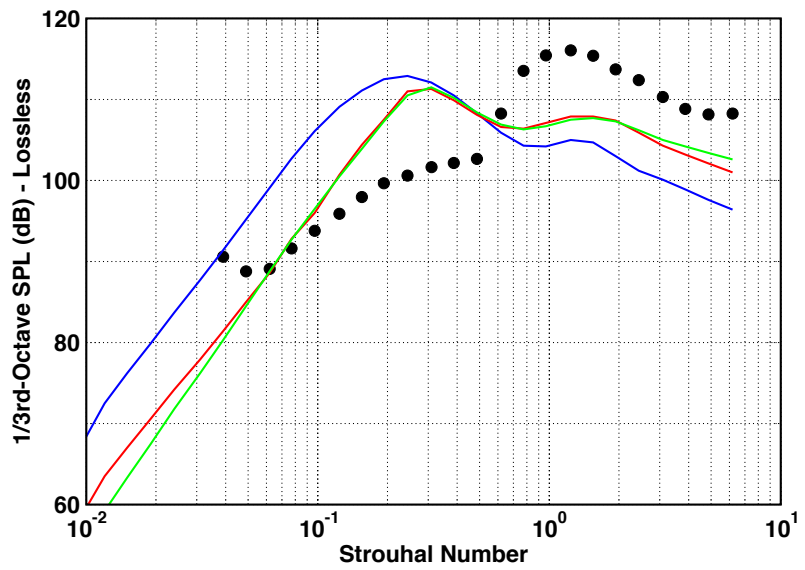

(f) $M_{j}=1.659, T_{t} / T_{\infty}=2.16, \beta=1.324, \theta=120$

Figure 10. 1/3-Octave spectra of the shock-associated noise component for measured data from two jets with shocks at 50, 90, and 120 degree inlet angles and distance $100 D$. The predictions from the original SAE broadband shockassociated noise model, the revised model with the EMD-derived $H$-spectrum, and the revised model with the curve fit $H$-spectrum are shown for comparison. 
the predicted spectrum was computed by averaging the errors computed for each $1 / 3$-octave band

$$
\text { Average Error }=\frac{1}{N} \sum_{i=1}^{N}\left|\operatorname{SPL}_{\text {pred }}\left(f_{i}\right)-\operatorname{SPL}_{\text {meas }}\left(f_{i}\right)\right|
$$

where $N$ is the number of included 1/3-octave bands. By taking the absolute value of the difference between predicted and measured sound pressure levels, a smaller average error requires relatively smaller errors across the entire spectrum. Another measure of error was computed using the overall sound pressure level (OASPL) using

$$
\text { OASPL Error }=\text { OASPL }_{\text {pred }}-\mathrm{OASPL}_{\text {meas }}
$$

The calculation of OASPL for this error determination was done over the same frequency range as that used to compute the average error. The OASPL error can be either positive or negative indicating that the predicted value is higher or lower, respectively, than the measured OASPL. These errors were computed separately for each inlet angle.

The errors were computed using equations (13) and (14). For the nominally $\beta=0.314$ cases, the error computation was limited to the frequency range where the Strouhal number was greater than or equal to 1.0. This was done because the model underpredicts the data at lower frequencies for lower $\beta$ conditions but is still fairly accurate at the peak of the shock-associated noise component spectrum and at higher frequencies. The lower frequencies of the total jet noise spectrum are due to mixing noise sources. Hence, the sum of the mixing noise model prediction and the shock noise model prediction in lower $\beta$ cases will give a reasonable prediction for the total noise spectrum. The $\beta=0.628$ cases were limited to Strouhal numbers greater than or equal to 0.4. All other higher $\beta$ cases had no Strouhal number range limitations. Plots of the errors as a function of the inlet angle are shown in Figure 11 for the original SAE model and for the revised model using the EMD-derived $H$-spectrum. The error results for the curve fit essentially directly overlap the EMD-derived results and therefore are not shown. The two lower $\beta$ results are shown separately due to their frequency limitations. These results are given in terms of the range of errors computed over the four cases at that $\beta$ value. The remaining 16 cases are plotted together with the values at each inlet angle averaged to obtain an average error within the range of computed errors.

The results for average error and OASPL error show that the revised model predictions generally has lower errors than the original SAE model predictions. Both models have typically larger errors at inlet angles greater than 100 degrees. The data in Figure 11 was used to determine an average decrease in error from the SAE model to the revised model. Also, the range of errors was used to compute the uncertainty in both model predictions. These results are shown in Table 2. The table shows that the revised model prediction is as good as the SAE model prediction with zero decrease in error to up to a $3.5 \mathrm{~dB}$ decrease in the average error for the revised model. For the most part, the revised model predictions have less uncertainty than the SAE model predictions.

Table 2. Average of errors and uncertainties computed from comparisons of predicted to measured shock-associated noise component spectra for both the SAE model and the revised model.

\begin{tabular}{|c||c|c|c||c|c|c||c|}
\hline \multicolumn{1}{|||}{} & \multicolumn{2}{l||}{ Average Error } & \multicolumn{2}{l||}{ OASPL Error } & \\
\hline & $\begin{array}{c}\text { Avg. Err. } \\
\text { Decrease }\end{array}$ & $\begin{array}{c}\text { SAE Mod. } \\
\text { Uncert. }\end{array}$ & $\begin{array}{c}\text { Rev. Mod. } \\
\text { Uncert. }\end{array}$ & $\begin{array}{c}\text { Avg. Err. } \\
\text { Decrease }\end{array}$ & $\begin{array}{c}\text { SAE Mod. } \\
\text { Uncert. }\end{array}$ & $\begin{array}{c}\text { Rev. Mod. } \\
\text { Uncert. }\end{array}$ & Conditions \\
\hline$\beta=0.314$ & 0.0 & \pm 1.04 & \pm 0.64 & 2.0 & \pm 4.2 & \pm 3.3 & $\theta \leq 100, f D / V_{j} \geq 1.0$ \\
$\beta=0.628$ & 0.5 & \pm 0.62 & \pm 0.33 & 0.7 & \pm 1.4 & \pm 1.4 & $\theta \leq 120, f D / V_{j} \geq 0.4$ \\
$\beta \geq 0.967$ & 3.5 & \pm 1.73 & \pm 1.36 & 1.4 & \pm 2.1 & \pm 1.7 & $\theta \leq 120, f D / V_{j}>0.0$ \\
\hline
\end{tabular}

Errors and uncertainties in decibels.

The error results listed above are for the data used to develop the revised shock-associated noise component prediction model. The revised model is now applied to jet conditions not included in the database of Table 1. The two supersonic jet conditions are listed in Table 3; a heated jet at $T_{t} / T_{\infty}=1.45$, less than the heated jet values in the database, and a higher temperature jet with $T_{t} / T_{\infty}=3.20$ using the smooth smc000 nozzle with low screech. The noise predictions were made with the inclusion of mixing noise from 


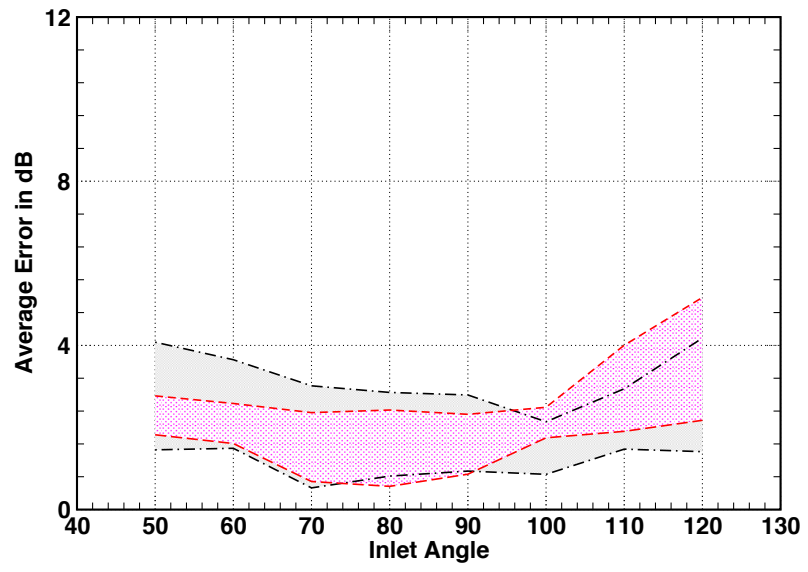

(a) $\beta=0.314$

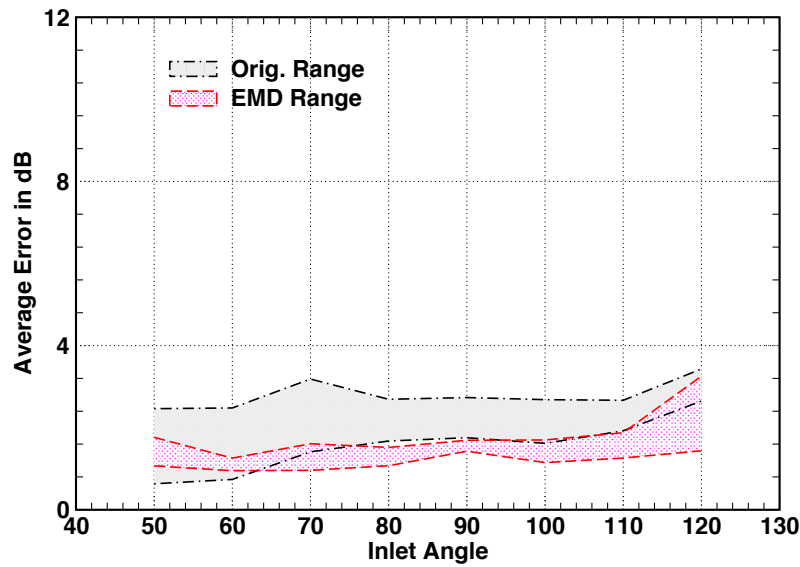

(c) $\beta=0.628$

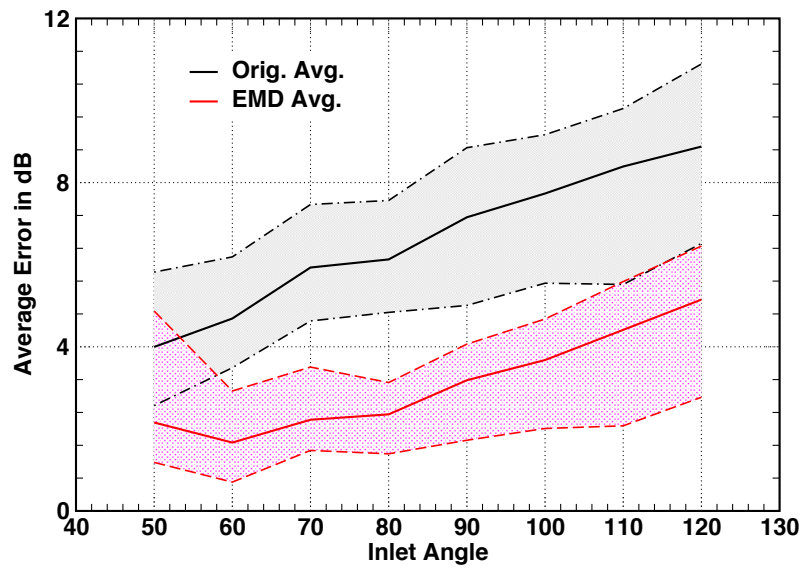

(e) $\beta \geq 0.967$

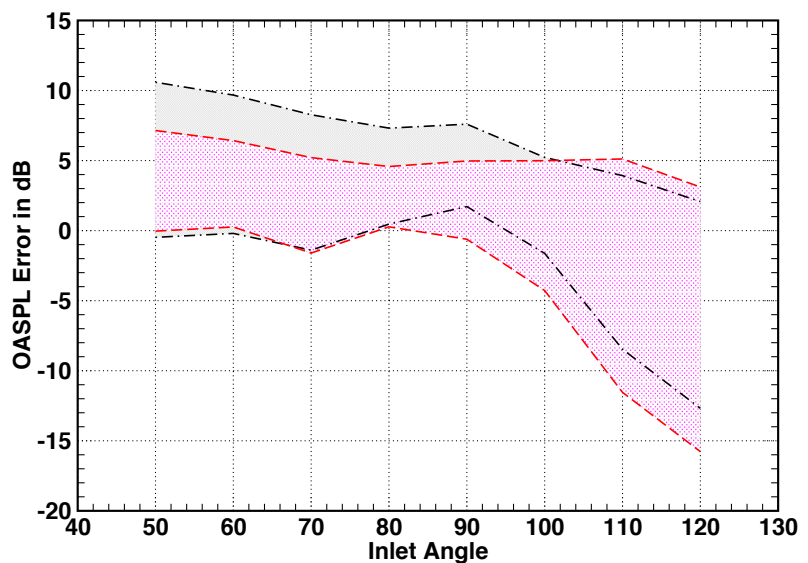

(b) $\beta=0.314$

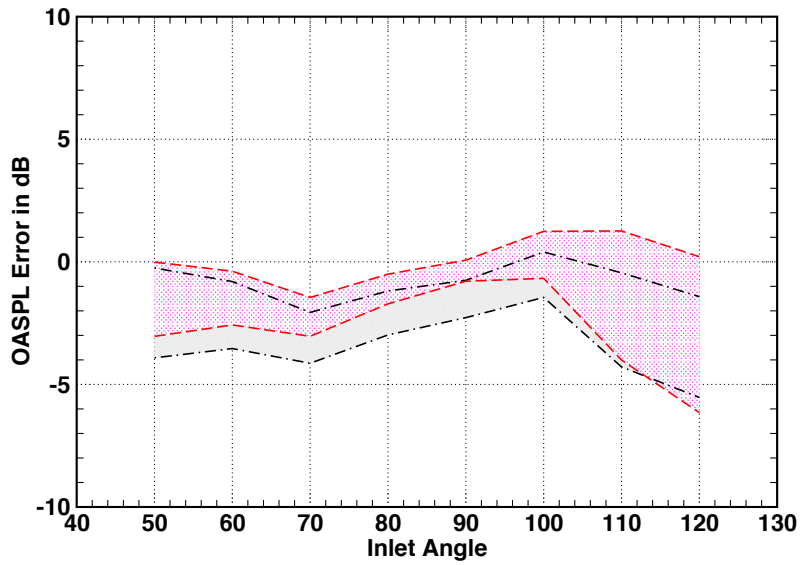

(d) $\beta=0.628$

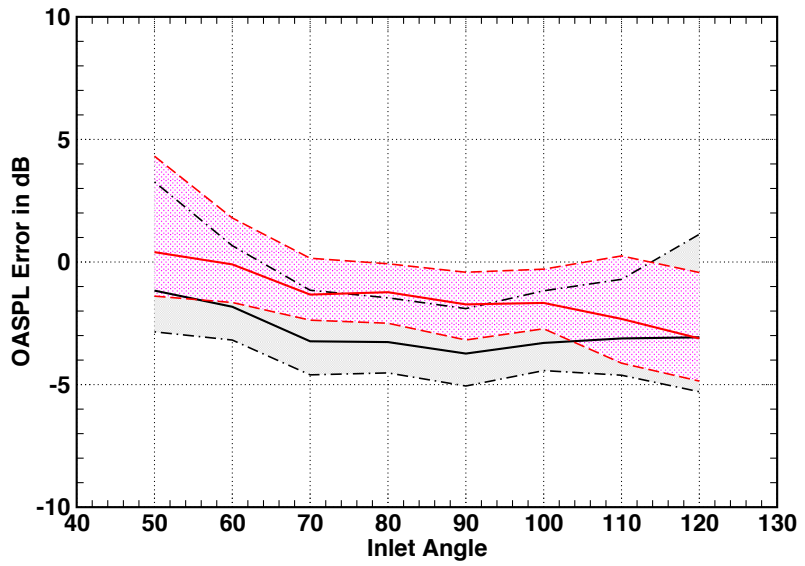

(f) $\beta \geq 0.967$

Figure 11. Summary of error between model predictions and measured data. Average error across the spectrum for the shock noise component on the left. Error in OASPL on the right. Results from prediction models minus measured data. 
Table 3. Test conditions for a convergent nozzle not listed in Table 1.

\begin{tabular}{|r|c|c|c|c|c|c|c|c|c|}
\hline Nozzle & $T_{t} / T_{\infty}$ & $\mathrm{NPR}$ & $M_{j}$ & $V_{j} / c_{\infty}$ & $\beta$ & $\gamma_{j}$ & $T_{\infty}(\mathrm{K})$ & $p_{\infty}(\mathrm{Pa})$ & $c_{\infty}(\mathrm{m} / \mathrm{s})$ \\
\hline smc021 & 1.45 & 3.653 & 1.497 & 1.500 & 1.114 & 1.3997 & 274.9 & 99811 & 332.31 \\
smc000 & 3.20 & 4.017 & 1.568 & 2.300 & 1.208 & 1.3752 & 276.3 & 99794 & 333.17 \\
\hline
\end{tabular}

the prediction model in SAE ARP $876 \mathrm{E} .{ }^{3}$ This shows how well the models predict the total noise spectrum where shock-associated noise dominates at the upstream angles and whether or not the shock noise prediction model's lack of accuracy matters as the angle moves toward downstream where mixing noise is more important. The comparison of the total noise prediction to measured data is shown in Figure 12 for both the SAE shock noise model prediction with the added mixing noise prediction from the SAE mixing noise model and the revised shock noise model prediction also with the added mixing noise prediction. At 90 degrees and upstream, the revised model clearly shows better spectral predictions, limiting the effect of the low frequency hump evident in the SAE model predicted spectrum and increasing the spectral levels at the peak and higher frequencies. For the cooler jet at the 120 degree inlet angle, Figure 12(e) shows the revised model gives a slightly better prediction while Figure 12(f) shows the hot jet spectrum is dominated by mixing noise and the accuracy of the shock-associated noise prediction is not relevant. The computed errors are shown in Table 4. The errors are lower for the revised model compared to the SAE model where shock-associated noise dominates at the upstream angles and about the same where mixing noise dominates.

Table 4. Computed errors from comparison of predicted to measured total jet noise spectra shown in Figure 12.

\begin{tabular}{|c||c|c||c|c|}
\hline \multicolumn{1}{|c||}{} & \multicolumn{4}{c|}{ Average Error } \\
\hline \multicolumn{1}{|c||}{} & \multicolumn{2}{c|}{$\beta=114$} & \multicolumn{2}{c|}{$\beta=1.208$} \\
\hline Inlet $\theta$ (Deg) & SAE Model & Rev. Model & SAE Model & Rev. Model \\
\hline 50 & 4.3 & 2.8 & 2.8 & 1.5 \\
90 & 4.3 & 2.5 & 3.3 & 2.0 \\
120 & 4.0 & 3.0 & 2.8 & 2.6 \\
\hline \multicolumn{1}{|c||}{} & \multicolumn{4}{c|}{ OASPL Error } \\
\hline 50 & -1.90 & -0.10 & -1.52 & -0.07 \\
90 & -2.73 & -0.62 & -2.37 & -1.55 \\
120 & -0.01 & +0.43 & +2.19 & +2.15 \\
\hline
\end{tabular}

Errors in decibels.

In summary, the proposed changes to the SAE shock-associated noise prediction model expressed in equations (6) to (9) with the associated parameter definitions are as follows:

1. The $\beta$ exponent $\eta$ is equal to 1 if $\beta>1$ or if $\beta \leq 1$, it equals 4 for $T_{t} / T_{\infty}<1.1$ or 5 for $T_{t} / T_{\infty} \geq 1.1$.

2. The eddy convection velocity coefficient $C_{0}$ is given as a function of the Strouhal number by equation (11).

3. The group source strength spectrum $H$ is given in terms of $\log (H)$ versus $\log (\sigma)$ by either interpolation from the values in Table 5, Appendix B, or by the curve fit equations (12). The tabulated values come from the residual of an empirical mode decomposition that gives the basic trend or shape of the spectrum with no a priori assumption about the spectrum shape. The piecewise curve fit equations and their points of connection were arbitrarily chosen to fit a curve to represent the data.

4. The cold jet results are $3 \mathrm{~dB}$ lower than the hot jet results. Replace tabulated or computed $\log (H)$ with $\log (H)-0.3$ when $T_{t} / T_{\infty}<1.1$. 


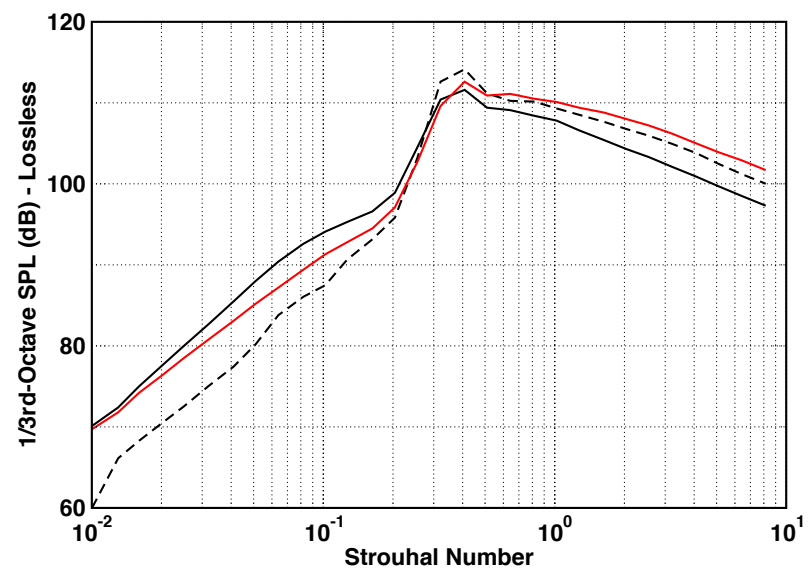

(a) $M_{j}=1.497, T_{t} / T_{\infty}=1.45, \beta=1.114, \theta=50$

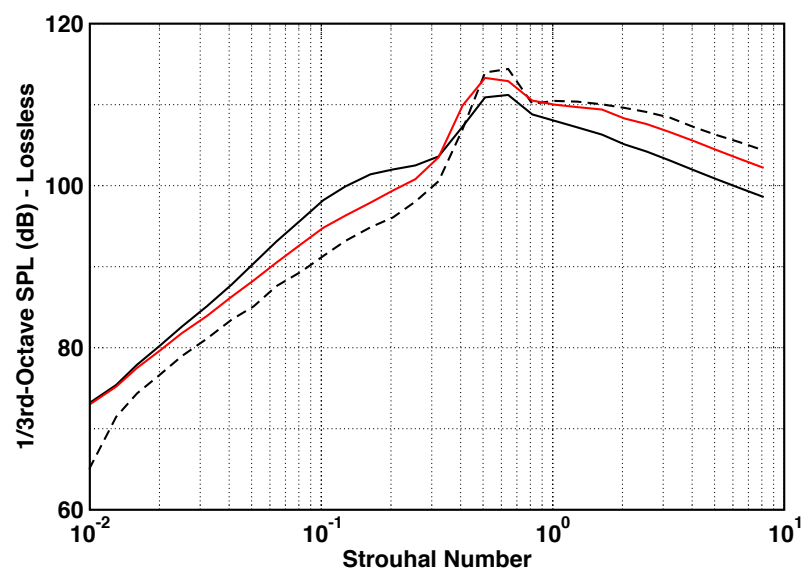

(c) $M_{j}=1.497, T_{t} / T_{\infty}=1.45, \beta=1.114, \theta=90$

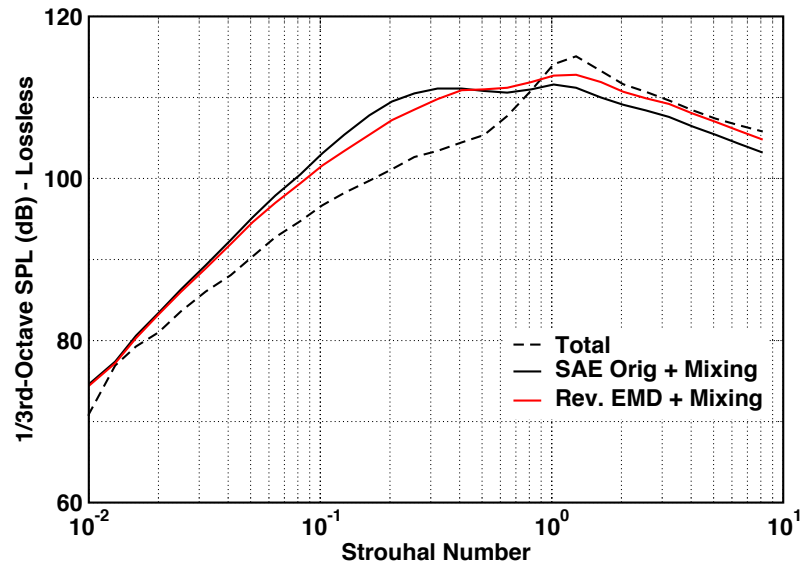

(e) $M_{j}=1.497, T_{t} / T_{\infty}=1.45, \beta=1.114, \theta=120$

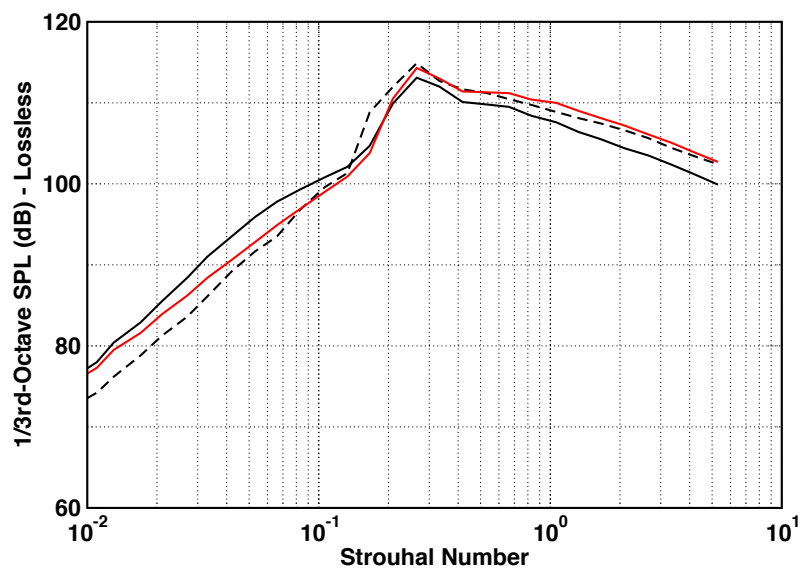

(b) $M_{j}=1.568, T_{t} / T_{\infty}=3.20, \beta=1.208, \theta=50$

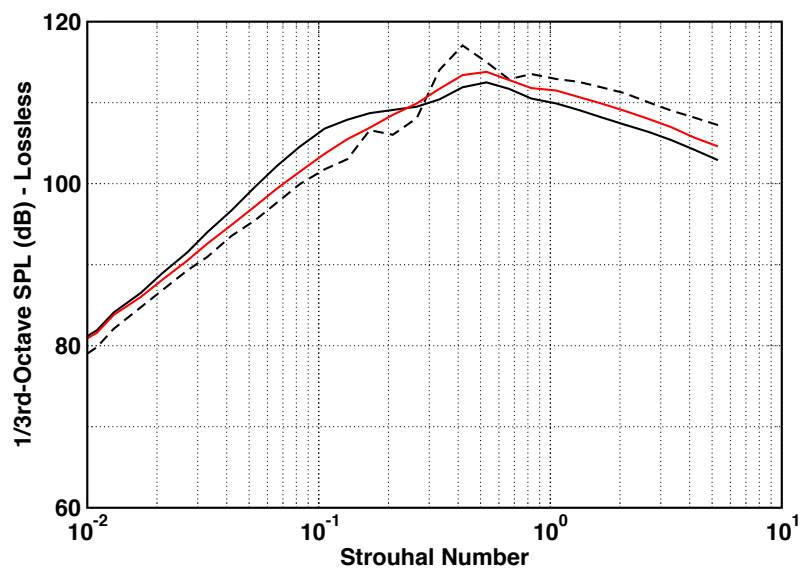

(d) $M_{j}=1.568, T_{t} / T_{\infty}=3.20, \beta=1.208, \theta=90$

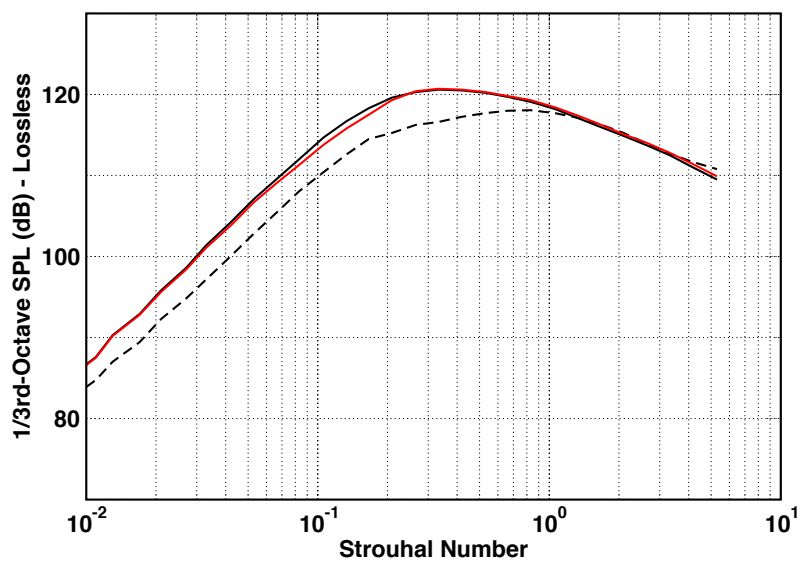

(f) $M_{j}=1.568, T_{t} / T_{\infty}=3.20, \beta=1.208, \theta=120$

Figure 12. 1/3-Octave spectra of the total noise for measured data from two jets with shocks at 50, 90 , and 120 degree inlet angles and distance $100 \mathrm{D}$. The predictions from the original SAE broadband shock-associated noise model and the revised model with the EMD-derived $H$-spectrum are shown for comparison. Both models are summed with the SAE mixing noise model to obtain the total predicted jet noise spectra. 


\section{Appendix A - Computation of Ratio of Specific Heats}

The ratio of specific heats in a supersonic jet at the fully expanded jet conditions depends on the jet temperature. Assuming that the jet flow is a calorically imperfect, thermally perfect gas, it is computed by iterating on the following equations: ${ }^{20}$

$$
\begin{gathered}
\mathrm{M}_{j(i)}=\left[\frac{2}{\gamma_{j(i-1)}-1}\left(\mathrm{NPR}^{\frac{\gamma_{j(i-1)}-1}{\gamma_{j(i-1)}}}-1\right)\right]^{\frac{1}{2}} \\
T_{j(i)}=\frac{T_{t}}{\left[1+\frac{\gamma_{j(i-1)}-1}{2} \mathrm{M}_{j(i)}^{2}\right]} \\
\gamma_{j(i)}=1+\frac{\gamma_{\text {perf }}-1}{1+\left(\gamma_{\text {perf }}-1\right)\left[\left(\frac{\Theta}{T_{j(i)}}\right)^{2} \frac{e^{\Theta / T_{j(i)}}}{\left(e^{\Theta / T_{j(i)}}-1\right)^{2}}\right]}
\end{gathered}
$$

where the nozzle pressure ratio, NPR, and total temperature, $T_{t}$, are known and fixed operating conditions, $\gamma_{j(0)}=\gamma_{\text {perf }}=1.4$ for air treated as a perfect gas, and

$$
\Theta=\left\{\begin{array}{l}
5500 . \quad, T \text { in degrees Rankine } \\
5500 . / 1.8, T \text { in degrees Kelvin }
\end{array}\right.
$$




\section{Appendix B $-H$-Spectrum table}

Table 5. Revised group source strength spectrum $H(\sigma)$.

\begin{tabular}{|l|l||c|c||c|c||c|c|}
\hline $\log _{10} \sigma$ & $\log _{10} H$ & $\log _{10} \sigma$ & $\log _{10} H$ & $\log _{10} \sigma$ & $\log _{10} H$ & $\log _{10} \sigma$ & $\log _{10} H$ \\
\hline 0.000 & -3.5655 & 0.625 & -0.8350 & 1.250 & -0.9419 & 1.875 & -1.5835 \\
0.025 & -3.4736 & 0.650 & -0.7547 & 1.275 & -0.9578 & 1.900 & -1.6118 \\
0.050 & -3.3813 & 0.675 & -0.7028 & 1.300 & -0.9763 & 1.925 & -1.6400 \\
0.075 & -3.2648 & 0.700 & -0.6697 & 1.325 & -0.9989 & 1.950 & -1.6683 \\
0.100 & -3.1415 & 0.725 & -0.6528 & 1.350 & -1.0231 & 1.975 & -1.6966 \\
0.125 & -3.0261 & 0.750 & -0.6488 & 1.375 & -1.0477 & 2.000 & -1.7249 \\
0.150 & -2.9135 & 0.775 & -0.6531 & 1.400 & -1.0742 & 2.025 & -1.7532 \\
0.175 & -2.8252 & 0.800 & -0.6638 & 1.425 & -1.0978 & 2.050 & -1.7815 \\
0.200 & -2.7293 & 0.825 & -0.6776 & 1.450 & -1.1205 & 2.075 & -1.8098 \\
0.225 & -2.6481 & 0.850 & -0.6952 & 1.475 & -1.1399 & 2.100 & -1.8381 \\
0.250 & -2.5495 & 0.875 & -0.7121 & 1.500 & -1.1617 & 2.125 & -1.8663 \\
0.275 & -2.4462 & 0.900 & -0.7323 & 1.525 & -1.1841 & 2.150 & -1.8946 \\
0.300 & -2.3262 & 0.925 & -0.7519 & 1.550 & -1.2107 & 2.175 & -1.9229 \\
0.325 & -2.1857 & 0.950 & -0.7731 & 1.575 & -1.2366 & 2.200 & -1.9512 \\
0.350 & -2.0466 & 0.975 & -0.7921 & 1.600 & -1.2677 & 2.225 & -1.9795 \\
0.375 & -1.9187 & 1.000 & -0.8103 & 1.625 & -1.2991 & 2.250 & -2.0078 \\
0.400 & -1.7948 & 1.025 & -0.8271 & 1.650 & -1.3346 & 2.275 & -2.0361 \\
0.425 & -1.6939 & 1.050 & -0.8417 & 1.675 & -1.3605 & 2.300 & -2.0644 \\
0.450 & -1.6027 & 1.075 & -0.8542 & 1.700 & -1.3857 & 2.325 & -2.0926 \\
0.475 & -1.5233 & 1.100 & -0.8667 & 1.725 & -1.4074 & 2.350 & -2.1209 \\
0.500 & -1.4252 & 1.125 & -0.8786 & 1.750 & -1.4420 & 2.375 & -2.1492 \\
0.525 & -1.3137 & 1.150 & -0.8910 & 1.775 & -1.4746 & 2.400 & -2.1775 \\
0.550 & -1.1790 & 1.175 & -0.9017 & 1.800 & -1.4986 & 2.425 & -2.2058 \\
0.575 & -1.0566 & 1.200 & -0.9146 & 1.825 & -1.5265 & 2.450 & -2.2341 \\
0.600 & -0.9327 & 1.225 & -0.9267 & 1.850 & -1.5552 & 2.475 & -2.2624 \\
& & & & & & 2.500 & -2.2907 \\
\hline
\end{tabular}




\section{References}

${ }^{1}$ Bridges, J. E., Khavaran, A., and Hunter, C. A., "Jet Noise Prediction," Assessment of NASA's Aircraft Noise Prediction Capability, edited by M. D. Dahl, NASA TP-2012-215653, chap. 8, 2012.

${ }^{2}$ Dahl, M. D., "Predictions of Supersonic Jet Mixing and Shock-Associated Noise Compared with Measured Far-Field Data," NASA TM-2010-216328, 2010.

${ }^{3}$ SAE, "Gas Turbine Jet Exhaust Noise Prediction," ARP876 Rev. E, SAE International, 2006.

${ }^{4}$ Zorumski, W. E., "Aircraft Noise Prediction Program Theoretical Manual, Parts 1 \& 2, (Revised)," NASA TM-83199, February 1982

${ }^{5}$ Bridges, J. and Brown, C. A., "Validation of the Small Hot Jet Acoustic Rig for Aeroacoustic Research," AIAA Paper No. 2005-2846, 2005.

${ }^{6}$ Bridges, J. and Wernet, M. P., "Measurements of the Aeroacoustic Sound Sources in Hot Jets," AIAA Paper No. 20033130, 2003.

${ }^{7}$ Brown, C. A. and Bridges, J., "Small Hot Jet Acoustic Rig Validation," NASA TM-2006-214234, 2006.

${ }^{8}$ Bridges, J. and Wernet, M. P., "Effect of Temperature on Jet Velocity Spectra," AIAA Paper No. 2007-3628, 2007.

${ }^{9}$ Khavaran, A. and Bridges, J., "SHJAR Jet Noise Data and Power Spectral Laws," NASA TM-2009-215608, 2009.

${ }^{10}$ Khavaran, A. and Bridges, J., "Development of Jet Noise Power Spectral Laws Using SHJAR Data," AIAA Paper No. 2009-3378, 2009.

${ }^{11}$ Bridges, J. E., Khavaran, A., and Hunter, C., "Assessment of Current Jet Noise Prediction Capabilities," AIAA Paper No. 2008-2933, 2008.

${ }^{12}$ Harper-Bourne, M. and Fisher, M. J., "The Noise from Shock Waves in Supersonic Jets," Noise Mechanisms, AGARDCP-131, 1974, pp. 11.1-11.13.

${ }^{13}$ Balsa, T. F., Gliebe, P. R., Kantola, R. A., Mani, R., Stringas, E. J., and Wang, J. F. C., "High Velocity Jet Noise Source Location and Reduction. Task 2. Theoretical Developments and Basic Experiments; Final Report," FAA-RD-76-79, II, FAA, 1978.

${ }^{14}$ Tester, B. J., Morris, P. J., Lau, J. C., and Tanna, H. K., "The Generation, Radiation and Prediction of Supersonic Jet Noise, Volume I," AFAPL-TR-78-85-Vol I, Air Force Aero Propulsion Laboratory, 1978.

${ }^{15}$ Harper-Bourne, M., "Jet Noise Turbulence Measurements," AIAA Paper No. 2003-3214, 2003.

${ }^{16}$ Morris, P. J. and Zaman, K. B. M. Q., "Velocity Measurements in Jets with Application to Noise Source Modeling," J. Sound Vib., Vol. 329, 2010, pp. 394-414.

${ }^{17}$ Dahl, M. D., "Turbulent Statistics from Time-Resolved PIV Measurements of a Jet Using Empirical Mode Decomposition," AIAA Paper No. 2012-2297, 2012.

${ }^{18}$ Huang, N. E., Shen, Z., Long, S. R., Wu, M. C., Shih, H. H., Zheng, Q., Yen, N.-C., Tung, C. C., and Liu, H. H., "The Empirical Mode Decomposition and the Hilbert Spectrum for Nonlinear and Non-Stationary Time Series Analysis," Proc. Roy. Soc. Lond. A, Vol. 454, 1998, pp. 903-995.

${ }^{19}$ Deneuville, P., "Simplified Prediction Method of Shock Cell Noise of Supersonic Jets from Conical Nozzles," SNECMA YKA No. 5982/76, Societe Nationale d'Edute et de Construction de Moteurs d'Avion, France, 1976.

${ }^{20}$ NACA Ames Research Staff, "Equations, Tables, and Charts for Compressible Flow," NACA Report 1135, 1953. 


\begin{tabular}{|c|c|c|}
\hline \multicolumn{2}{|c|}{ REPORT DOCUMENTATION PAGE } & $\begin{array}{l}\text { Form Approved } \\
\text { OMB No. 0704-0188 }\end{array}$ \\
\hline \multicolumn{3}{|c|}{$\begin{array}{l}\text { The public reporting burden for this collection of information is estimated to average } 1 \text { hour per response, including the time for reviewing instructions, searching existing data sources, gathering and maintaining the } \\
\text { data needed, and completing and reviewing the collection of information. Send comments regarding this burden estimate or any other aspect of this collection of information, including suggestions for reducing this } \\
\text { burden, to Department of Defense, Washington Headquarters Services, Directorate for Information Operations and Reports (0704-0188), } 1215 \text { Jefferson Davis Highway, Suite } 1224 \text {, Allington, VA } 22222-24302 \text {. } \\
\text { Respondents should be aware that notwithstanding any other provision of law, no person shall be subject to any penalty for failing to comply with a collection of information if it does not display a currently valid OMB } \\
\text { control number. } \\
\text { PLEASE DO NOT RETURN YOUR FORM TO THE ABOVE ADDRESS. }\end{array}$} \\
\hline $\begin{array}{l}\text { 1. REPORT DATE (DD-MM-YYYY) } \\
01-02-2014\end{array}$ & $\begin{array}{l}\text { 2. REPORT TYPE } \\
\text { Technical Memorandum }\end{array}$ & 3. DATES COVERED (From - To) \\
\hline \multirow{3}{*}{\multicolumn{2}{|c|}{$\begin{array}{l}\text { 4. TITLE AND SUBTITLE } \\
\text { Analysis of a Shock-Associated Noise Prediction Model Using Measured Jet Far-Field Noise } \\
\text { Data }\end{array}$}} & 5a. CONTRACT NUMBER \\
\hline & & 5b. GRANT NUMBER \\
\hline & & 5c. PROGRAM ELEMENT NUMBER \\
\hline \multirow{3}{*}{\multicolumn{2}{|c|}{$\begin{array}{l}\text { 6. AUTHOR(S) } \\
\text { Dahl, Milo, D.; Sharpe, Jacob, A. }\end{array}$}} & 5d. PROJECT NUMBER \\
\hline & & 5e. TASK NUMBER \\
\hline & & $\begin{array}{l}\text { 5f. WORK UNIT NUMBER } \\
\text { WBS 475122.02.03.05.01 }\end{array}$ \\
\hline \multicolumn{2}{|c|}{$\begin{array}{l}\text { 7. PERFORMING ORGANIZATION NAME(S) AND ADDRESS(ES) } \\
\text { National Aeronautics and Space Administration } \\
\text { John H. Glenn Research Center at Lewis Field } \\
\text { Cleveland, Ohio 44135-3191 }\end{array}$} & $\begin{array}{l}\text { 8. PERFORMING ORGANIZATION } \\
\text { REPORT NUMBER } \\
\text { E-18842 }\end{array}$ \\
\hline \multirow{2}{*}{\multicolumn{2}{|c|}{$\begin{array}{l}\text { 9. SPONSORING/MONITORING AGENCY NAME(S) AND ADDRESS(ES) } \\
\text { National Aeronautics and Space Administration } \\
\text { Washington, DC 20546-0001 }\end{array}$}} & $\begin{array}{l}\text { 10. SPONSORING/MONITOR'S } \\
\text { ACRONYM(S) } \\
\text { NASA }\end{array}$ \\
\hline & & $\begin{array}{l}\text { 11. SPONSORING/MONITORING } \\
\text { REPORT NUMBER } \\
\text { NASA/TM-2014-218109 }\end{array}$ \\
\hline \multicolumn{3}{|c|}{$\begin{array}{l}\text { 12. DISTRIBUTION/AVAILABILITY STATEMENT } \\
\text { Unclassified-Unlimited } \\
\text { Subject Category: } 71 \\
\text { Available electronically at http://www.sti.nasa.gov } \\
\text { This publication is available from the NASA Center for AeroSpace Information, 443-757-5802 }\end{array}$} \\
\hline
\end{tabular}

\section{SUPPLEMENTARY NOTES}

\section{ABSTRACT}

A code for predicting supersonic jet broadband shock-associated noise was assessed using a database containing noise measurements of a jet issuing from a convergent nozzle. The jet was operated at 24 conditions covering six fully expanded Mach numbers with four total temperature ratios. To enable comparisons of the predicted shock-associated noise component spectra with data, the measured total jet noise spectra were separated into mixing noise and shock-associated noise component spectra. Comparisons between predicted and measured shock-associated noise component spectra were used to identify deficiencies in the prediction model. Proposed revisions to the model, based on a study of the overall sound pressure levels for the shock-associated noise component of the measured data, a sensitivity analysis of the model parameters with emphasis on the definition of the convection velocity parameter, and a least-squares fit of the predicted to the measured shock-associated noise component spectra, resulted in a new definition for the source strength spectrum in the model. An error analysis showed that the average error in the predicted spectra was reduced by as much as $3.5 \mathrm{~dB}$ for the revised model relative to the average error for the original model.

\section{SUBJECT TERMS}

Jet noise; Noise prediction; Propulsion noise; Noise; Shocks; Supersonic jets; Accuracy

\begin{tabular}{|c|c|c|c|c|c|}
\hline \multicolumn{3}{|c|}{ 16. SECURITY CLASSIFICATION OF: } & \multirow{2}{*}{$\begin{array}{l}\text { 17. LIMITATION OF } \\
\text { ABSTRACT } \\
\text { UU }\end{array}$} & \multirow{2}{*}{$\begin{array}{l}\text { 18. NUMBER } \\
\text { OF } \\
\text { PAGES } \\
30\end{array}$} & \multirow{2}{*}{$\begin{array}{l}\text { 19a. NAME OF RESPONSIBLE PERSON } \\
\text { STI Help Desk (email:help@sti.nasa.gov) } \\
\text { 19b. TELEPHONE NUMBER (include area code) } \\
\text { 443-757-5802 }\end{array}$} \\
\hline $\begin{array}{l}\text { a. REPORT } \\
U\end{array}$ & $\begin{array}{l}\text { b. ABSTRACT } \\
\mathrm{U}\end{array}$ & $\begin{array}{l}\text { c. THIS } \\
\text { PAGE } \\
\text { U }\end{array}$ & & & \\
\hline
\end{tabular}



